\title{
The Role of Sirtuins in Kidney Diseases
}

\author{
Yu Ah Hong ${ }^{1}{ }^{\mathbb{D}}$, Ji Eun Kim ${ }^{2} \mathbb{D}$, Minjee Jo ${ }^{2}$ and Gang-Jee Ko ${ }^{2, *}$ \\ 1 Department of Internal Medicine, College of Medicine, The Catholic University of Korea, Daejeon St. Mary \\ Mary's Hospital, Daejeon 34943, Korea; amorfati@catholic.ac.kr \\ 2 Department of Internal Medicine, Korea University College of Medicine, Korea University Guro Hospital, \\ Seoul 08308, Korea; beeswaxag@naver.com (J.E.K.); minjeeyoyo@naver.com (M.J.) \\ * Correspondence: lovesba@korea.ac.kr; Tel.: +82-2-2626-3039
}

Received: 2 August 2020; Accepted: 7 September 2020; Published: 12 September 2020

check for updates

\begin{abstract}
Sirtuins (SIRTs) are class III histone deacetylases (HDACs) that play important roles in aging and a wide range of cellular functions. Sirtuins are crucial to numerous biological processes, including proliferation, DNA repair, mitochondrial energy homeostasis, and antioxidant activity. Mammals have seven different sirtuins, SIRT1-7, and the diverse biological functions of each sirtuin are due to differences in subcellular localization, expression profiles, and cellular substrates. In this review, we summarize research advances into the role of sirtuins in the pathogenesis of various kidney diseases including acute kidney injury, diabetic kidney disease, renal fibrosis, and kidney aging along with the possible underlying molecular mechanisms. The available evidence indicates that sirtuins have great potential as novel therapeutic targets for the prevention and treatment of kidney diseases.
\end{abstract}

Keywords: sirtuins; kidney; acute kidney injury; diabetic nephropathy; chronic kidney disease; aging kidney

\section{Introduction}

Sirtuins (SIRTs) are a family of nicotinamide adenine dinucleotide (NAD) ${ }^{+}$-dependent class III histone deacetylases (HDACs) that use the coenzyme $\mathrm{NAD}^{+}$to deacetylate lysine residues in histone and non-histone proteins. Due to their ability to target post-translational acyl modifications of various cellular substrates, sirtuins are crucial to numerous biological processes including proliferation, DNA repair, mitochondrial energy homeostasis, and antioxidant activity [1]. Silent information regulator 2 (SIR2) was the first sirtuin discovered and was originally found in Saccharomyces cerevisiae [2]. SIR2 is critical for transcriptional silencing in budding S. cerevisiae and extension of the lifespan of mother cells through suppression of toxic recombinant DNA circle formation, as well as other processes including the management of molecules damaged by oxidative stress [3]. Seven different sirtuin proteins localized to different subcellular compartments have been identified in mammals [4]. SIRT1 and SIRT2 are distributed in both the nucleus and cytoplasm. SIRT3, SIRT4, and SIRT5 are mainly present in the mitochondria, while SIRT6 and SIRT7 are primarily found in the nucleus $[1,5]$. The diverse biological functions of the various sirtuins are attributed to differences in subcellular localization, expression profiles, and cellular substrates.

\section{Molecular Targets of Sirtuins}

SIRT1, as the first sirtuin identified in mammals, has been the most widely investigated. Although SIRT1 is mainly present in the nucleus, it can translocate into the cytoplasm under specific conditions, such as ischemic stress or embryonic development [6,7]. In the kidney, SIRT1 is widely expressed in tubular cells and podocytes [8]. At the cellular level, SIRT1 may play important roles in several biological processes, including energetic homeostasis [9], apoptosis [10], 
mitochondrial biogenesis [11], and autophagy [12]. SIRT1 mediates the longevity effect of caloric restriction through regulation of glucose and lipid metabolism $[9,13]$. Caloric restriction increases the $\mathrm{NAD}^{+} / \mathrm{NADH}$ ratio and subsequently SIRT1 activity [14]. Using the coenzyme NAD ${ }^{+}$, SIRT1 enhances chromatin silencing and transcriptional repression through deacetylation of histones [15]. SIRT1 can directly deacetylate histone lysines H4K16 (H4 Lys16), H3K9 (H3 Lys9), H3K14 (H3 Lys14), and H1K26 (H1 Lys26) upon recruitment to chromatin [16]. SIRT1 acts as the key transcriptional modulator of cell survival via regulation of p53 [17], nuclear factor- $\mathrm{kB}$ (NF-kB) p65 [18], signal transducer and activator of transcription 3 (STAT3) [19], and the Forkhead boX class O (FoxO) family [20]. SIRT1 regulates the cellular response to hypoxic stress through deacetylation of hypoxia-induced factor $1 \alpha$ (HIF-1 $\alpha$ ) [21,22]. SIRT1 also activates peroxisome proliferator-activated receptor gamma (PPAR $\gamma$ ) through deacetylation of PPAR $\gamma$ coactivator-1 $\alpha$ (PGC-1 $\alpha$ ) [23,24]. In addition, SIRT1 regulates cellular homeostasis through its activation of adenosine monophosphate-activated protein kinase (AMPK) via liver kinase B1 (LKB1) and inhibition of the mammalian target of rapamycin (mTOR) [25,26]. SIRT1 also accelerates deacetylation and nuclear translocation of $\beta$-catenin and regulates the $\mathrm{Wnt} / \beta$-catenin transcriptional pathway [27].

SIRT2 is a cytoplasmic sirtuin that is co-localized with microtubules and deacetylates the major component of microtubules [28]. However, SIRT2 has also been observed in the nucleus and mitochondria, and its translocation to the nucleus may indicate an important epigenetic role [29]. SIRT2 has been shown to deacetylate several substrates including histone lysines H4K16 [30], H3K56 (H3 Lys56) [31], $\alpha$-tubulin [28], PR-Set7 [32], phosphoenolpyruvate carboxykinase 1 (PEPCK1) [33], NF-KB p65 [34], and FoxO family proteins [35,36], and is also involved in the regulation of the cell cycle, DNA repair, and stress responses [30]. SIRT2 regulates binding of p65 to the promoters of anti-inflammatory chemokines such as C-X-C motif chemokine ligand 2 (CXCL2) and CC motif chemokine ligand 2 (CCL2) [34]. SIRT2 also regulates insulin-induced protein kinase B (PKB/AKT) activation via constitutive phosphoinositide 3-kinase (PI3K) activity, and this regulation is involved in AMPK-dependent SIRT2 phosphorylation [37]. In addition, SIRT2 is a central regulator of the defense mechanism against reactive oxidative species (ROS) through FoxO3a deacetylation [36]. In the kidney, SIRT2 is mainly expressed in proximal epithelial tubular cells [34].

SIRT3 is the best characterized among mitochondrial sirtuins. SIRT3 is normally localized inside the mitochondria, but can translocate into the nucleus under stressful conditions, along with overexpression of SIRT5 [38]. SIRT3 is a NAD ${ }^{+}$-dependent deacetylase in mitochondria that regulates energy metabolism; the anti-oxidative defense system; lipid metabolism; and longevity via deacetylation of various substrates including acetyl-coenzyme A synthetase 2 (ACSS2) [39], glutamate dehydrogenase (GDH) [40], and superoxide dismutase 2 (SOD2) [41]. SIRT3 also reduces levels of ROS through regulation of NF-kB [42], AMPK [43], PGC-1 $\alpha$ [44], and FoxO3a [45]. SIRT3 regulates the acetylation status of multiple proteins to improve function, including those associated with fatty acid oxidation, ketogenesis, amino acid catabolism, and urea and tricarboxylic acid cycles, in addition to mitochondrial regulation $[40,46]$. In the kidney, SIRT3 has been described as a crucial regulator of mitochondrial dynamics in proximal epithelial tubular cells [47].

SIRT4, the second mitochondrial sirtuin, has been observed in the mitochondrial matrix where it binds to proteins in similar pathways to those regulated by SIRT3. SIRT4 exhibits $\mathrm{NAD}^{+}$-dependent adenosine diphosphate (ADP)-ribosyltransferase activity and inhibits GDH activity through ADP-ribosylation [48]. SIRT4 is also a lysine deacetylase and can remove multiple derivatives of methylglutaryl from lysine residues to regulate leucine metabolism [49]. However, reduction of SIRT4 under conditions of nutrient deprivation coordinates the use of fatty acids as an energy source, suggesting that SIRT4 might antagonize the dietary restriction-mediated effects of SIRT1 and SIRT3. SIRT4 also suppresses fatty acid oxidation through inhibition of malonyl CoA decarboxylase (MCD) [50], peroxisome proliferator-activated receptor $\alpha(\operatorname{PPAR} \alpha)$ [51], and AMPK signaling [52]. SIRT4 also acts as a tumor suppressor, regulating the cellular metabolic response to DNA damage via repression of glutamine metabolism [53]. However, little is known about the role of SIRT4 in the kidney [54]. 
SIRT5, the third mitochondrial sirtuin, was thought to localize primarily to mitochondria [55]. However, several studies have demonstrated that SIRT5 is also present in the cytosol, peroxisomes, and nucleus [56-58]. SIRT5 was initially described as a mitochondrial deacetylase, but it has minimal deacetylase activity [59]. Recent studies have reported that SIRT5 shows distinct affinity for negatively charged acyl lysine modifications, and acts as a prominent cellular desuccinylase, demalonylase, and deglutarylase, thereby regulating various metabolic pathways [59,60]. Pathway analysis identified multiple target pathways of SIRT5 including fatty acid oxidation, branched-chain amino acid catabolism, the citric acid cycle, adenosine triphosphate (ATP) synthesis, oxidative phosphorylation (OXPHOS), stress responses, ketogenesis, and pyruvate metabolism [61]. The absence of SIRT5 led to hypersuccinylation of mitochondrial proteins in the kidney $[62,63]$ and increased blood ammonia levels [64], suggesting that SIRT5 may play roles in renal and liver metabolism. A recent study revealed that SIRT5 is highly expressed in proximal epithelial tubular cells [65]. However, the function of SIRT5 in the kidney remains poorly understood.

SIRT6 is predominantly a nuclear protein and deacetylates diverse proteins, including H3K9 and H3K56 [66]. SIRT6 exhibits both deacetylase and mono-ADP-ribosyltransferase activities [67]. Like other sirtuins, SIRT6 regulates longevity via deacetylation of several transcription factors associated with DNA repair, glucose and lipid metabolism, cellular senescence, and inflammation [68-71]. SIRT6 also functions as a corepressor of HIF- $1 \alpha$, suppressing glucose uptake and glycolysis [70]. In the kidney, SIRT6 plays an important role in podocyte injury and renal fibrosis in podocytes and proximal epithelial tubular cells [72-74].

SIRT7 is localized to the nucleus and has $\mathrm{NAD}^{+}$-dependent HDAC activity [75]. SIRT7 appears to exhibit relatively weak and substrate-specific deacetylase activity. The known deacetylation substrates of SIRT7 are only H3K18 (H3 Lys18), p53, polymerase-associated factor 53 (PAF53), the nucleolar protein nucleophosmin (NPM1), and GA-binding protein- $\beta-1$ (GABP- $\beta 1$ ) [76]. SIRT7 deficiency is associated with a high mutation rate, increased sensitivity to DNA damage, and apoptosis. These findings suggest that SIRT7 regulates genome stability through its effects on transcriptional regulation, DNA replication, and DNA repair [77,78]. In the kidney, SIRT7 is expressed in proximal tubules and collecting ducts [79]. However, the role of SIRT7 in kidney injury remains unclear.

\section{The Role of Sirtuins in Renal Disease}

\subsection{Sirtuins in Acute Kidney Injury}

Interest in the role of sirtuins in the pathophysiology of various renal diseases has grown recently. Given the tubular expression of sirtuins and their modulating effects on oxidative stress, inflammation, and mitochondrial dysfunction, they are likely to be involved in the pathogenesis of acute kidney injury (AKI) [80].

\subsubsection{Sirtuins in Ischemia/Reperfusion-Induced Kidney Injury}

Greater susceptibility to injury caused by ischemia/reperfusion (I/R) in aging kidneys raises the possibility that sirtuins may play a role in the pathogenesis of $I / R$-induced kidney injury. SIRT1 overexpression was associated with enhanced resistance to kidney injury after $I / R$, whereas the loss of one SIRT1 allele aggravated kidney injury following I/R [81]. SIRT1 attenuated I/R-induced kidney injury along with activation of anti-oxidant pathways such as nuclear factor erythroid 2-related factor 2 (Nrf2)/heme oxygenase-1 (HO-1) signaling [82] and reduction of p53 expression and apoptosis [81]. SIRT1 also attenuated I/R-induced kidney injury by stimulating mitochondrial biogenesis. Treatment with SRT1720, an SIRT1 activator, restored renal ATP levels through reduction of mitochondrial mass, nitrosative stress, and inflammation, leading to attenuation of I/R-induced kidney injury [11]. Promotion of mitochondrial biogenesis and PGC-1 $\alpha$ activation by activators of SIRT1 has also been proposed as repair mechanisms after I/R-induced kidney injury [83]. 
I/R injury was found to increase SIRT3 expression in the kidney. Given that SIRT3 is mainly localized in the mitochondrial matrix, SIRT3 may affect the course of I/R-induced kidney injury, which is associated with mitochondrial dysfunction. SIRT3 overexpression was found to confer renal protection via the suppression of superoxide generation [84]. Reduced expression of SIRT3 was associated with increased severity of I/R-induced kidney injury, while restoration of SIRT3 reversed this damage by modulating mitochondrial homeostasis through the AMPK/PGC-1 $\alpha$ pathway [85]. A recent study reported that SIRT5 was highly expressed in both the mitochondria and peroxisomes of proximal tubular cells, but the opposite trend was observed in I/R-induced kidney injury compared to other types of sirtuins, as the loss of SIRT5 function led to renoprotective effects after I/R injury; shifting of fatty acid oxidation from the mitochondria to the peroxisome under the control of SIRT5 was suggested as the underlying mechanism. In contrast, SIRT6 expression was negatively correlated with the degree of hypoxia-induced tubular cell injury and inflammation of tubular epithelial cells [86]. The differing effect of each sirtuin on I/R-induced kidney injury should be elucidated through future researches.

\subsubsection{Sirtuins in Cisplatin-Induced Acute Kidney Injury}

Cisplatin-induced kidney injury decreases mitochondrial number and function, and also increases production of ROS. Given the core role of sirtuins in mitochondrial biogenesis and integrity, the role of sirtuins has been more extensively studied in cisplatin-induced AKI compared to other causes of AKI. Renal tubule-specific SIRT1 transgenic mice showed attenuation of functional and histological measures of kidney injury after cisplatin treatment, which was attributed to decreases in cisplatin-induced oxidative stress and apoptosis [87]. Pharmacologic activation of SIRT1 was also associated with the attenuation of cisplatin-induced AKI via modulation of oxidative stress and inflammation through the NF-KB and p53 signaling pathways [88-90]. Recent studies have highlighted the renoprotective activity of SIRT3 in cisplatin-induced AKI through modulation of mitochondrial dysfunction. Loss of SIRT3 function in mice led to aggravation of renal function deterioration after cisplatin treatment, and attenuation of cisplatin-induced kidney injury through pharmacologic activation of SIRT3, which was observed in wild-type mice, did not occur in SIRT3-deficient mice. In tubular cells, reduced SIRT3 expression after cisplatin treatment resulted in mitochondrial fragmentation, while activation of SIRT3 expression reversed the injury and preserved mitochondrial integrity [91]. The renoprotective role of SIRT3 in cisplatin-induced AKI through modulation of mitochondrial dysfunction has been further demonstrated in other studies [92,93]. One of nuclear sirtuins, SIRT6 knockout mice exhibited aggravation of cisplatin-induced kidney injury, while SIRT6 attenuated renal inflammation and apoptosis by deacetylating H3K9 and inhibiting expression of extracellular-signal-regulated kinase (ERK)-1/2 [94].

In contrast to SIRT1, SIRT3, and SIRT6, the absence of SIRT2 and SIRT7, not their overexpression, significantly ameliorated cisplatin-induced AKI by decreasing inflammation and apoptosis through modulation of p38 and c-Jun N-terminal kinase (JNK) $[79,90]$. Conflicting findings have been reported regarding the role of SIRT5 in cisplatin-induced AKI. In one study of renal tubular cells, SIRT5 overexpression was found to attenuate cisplatin-induced apoptosis and mitochondrial injury through regulation of Nrf2/HO-1 and B-cell lymphoma 2 (Bcl-2) [95]. However, another study reported that deficiency of SIRT5 function in mice significantly improved renal function and tubular damage in cisplatin-induced AKI through peroxisomal fatty acid oxidation of proximal tubules [65]. The exact role of SIRT5 in cisplatin-induced AKI requires further elucidation.

\subsubsection{Sirtuins in Other Types of Acute Kidney Injury}

The immunomodulatory function of most sirtuins has been shown to relieve sepsis-induced AKI. Overexpression of SIRT1 and SIRT6 was associated with alleviation of tubular injury induced by lipopolysaccharide treatment in an animal model of cecal ligation and puncture [96,97]. Similar results were obtained from sepsis-induced AKI model treated with resveratrol, a sirtuin activator [98]. The renoprotective effect of sirtuins in sepsis-induced AKI was accompanied by suppression of 
inflammasome activation and promotion of autophagy. However, consistent with cisplatin-induced AKI, loss of SIRT2 function in mice improved renal function and renal tubular injury after lipopolysaccharide treatment [34].

The role of sirtuins has been also demonstrated in contrast-induced nephropathy (CIN), which is the third leading cause of hospital-acquired AKI. It has been reported that oxidative stress associated with superoxide production and related pathways is involved in the pathogenesis of CIN [99], which is modulated by the level of sirtuin expression. We previously demonstrated that SIRT1 activation by resveratrol treatment attenuated CIN via modulation of oxidative stress and apoptosis through activation of PGC- $1 \alpha /$ FoxO1 signaling [100]. Another study demonstrated that SIRT3 deficiency aggravated CIN [101], whereas activation of the SIRT3-Nrf2 pathway alleviated CIN [102]. Further investigation into the exact roles of sirtuins in various settings of AKI is warranted.

\subsection{Sirtuins in the Aging Kidney}

Aging is a multifactorial process characterized by progressive decline in physiological function. The kidney is a typical target organ of age-associated tissue damage, and the increased incidence of chronic kidney disease (CKD) in elderly is an emerging health problem worldwide [103]. Various sirtuins have been demonstrated to mitigate kidney aging. SIRT1 expression was found to be reduced in aging kidneys, and this change was associated with changes in the expression of other target molecules such as PGC-1 $\alpha /$ estrogen-related receptor- $1 \alpha$ (ERR-1 $\alpha)$, PPAR $\alpha$, Klotho, and HIF-1 $\alpha$ [104-106]. Recently, podocyte-specific reduction of SIRT1 was found to accelerate kidney injury in aging mice [107]. Therefore, SIRT1 is believed as a potential target for treatment of kidney aging.

Caloric restriction has been shown to extend lifespan and may affect numerous cellular aspects of kidney aging. Kume et al. demonstrated that long-term caloric restriction from one to two years in mice promoted SIRT1 expression in aging kidneys, which resulted in attenuation of hypoxia-induced kidney injury via SIRT1-mediated deacetylation of FoxO3a and activation of autophagy [12]. Even short-term activation of SIRT1 through caloric restriction promoted autophagy and reduced mitochondrial oxidative damage in 25-month-old rats [108]. SIRT1 and its target proteins may play an important role in renoprotection of aging kidneys, which is accomplished through stimulation of autophagy. Pharmacologically induced SIRT1 activation significantly reduced tubulointerstitial fibrosis and improved renal function through enhancement of Nrf2/HO-1 signaling and AMPK/PGC- $1 \alpha$ signaling [109].

Along with other sirtuins, SIRT3 has been reported to act as an essential regulator of cell senescence. SIRT3 is associated with renin-angiotensin-aldosterone system (RAAS) activation, which is known to play a role in kidney aging. In kidneys of aged mice, angiotensin II (Ang II) type 1 receptor $\left(\mathrm{AT}_{1} \mathrm{R}\right)$ deletion upregulated nicotinamide phosphoribosyltransferase (Nampt) and SIRT3 and resulted in markedly prolonged lifespan. Ang II treatment downregulated SIRT3 expression in tubular epithelial cells, and this effect was inhibited by $\mathrm{AT}_{1}$ antagonist administration. These findings suggest a biochemical link between Ang II and SIRT3 through $\mathrm{AT}_{1} \mathrm{R}$ in aging kidneys [110]. However, a recent study reported conflicting results: this study found that expression of SIRT1 and Nampt expression, but not SIRT3, was significantly reduced in the kidneys of aged mice with $\mathrm{AT}_{1} \mathrm{R}_{\text {-associated }}$ protein (ATRAP) deletion [111]. Although the role of SIRT3 in kidney aging via the Ang II-AT ${ }_{1} R$ signaling pathway remains unclear, SIRT3 deficiency is known to cause severe renal fibrosis in aging kidneys associated with increased transforming growth factor- $\beta 1$ (TGF- $\beta 1$ ) expression and hyperacetylation of glycogen synthase kinase-3 $\beta$ (GSK-3 $\beta$ ), resulting in phosphorylation of Smad3, c-Jun, and $\beta$-catenin [112]. SIRT6 activation due to caloric restriction also attenuated age-associated kidney injury through inhibition of the proinflammatory NF-kB signaling pathway [113]. Together, these findings indicate that sirtuins play a role in attenuating tissue injury in aging kidneys, likely via attenuation of oxidative stress and inflammation, and it supports that the investigation of sirtuins should be done as therapeutic targets for kidney aging. 


\subsection{Sirtuins in Diabetic Kidney Disease}

Caloric restriction not only slows aging and increases lifespan, but also increases insulin sensitivity $[114,115]$. In a clinical study, fasting glucose levels and insulin resistance improved after a 12-week intensive weight reduction program based on caloric restriction among obese individuals with advanced diabetic nephropathy (DN), and also led to improvement in kidney function [116]. Dietary restriction in diabetic rat models increased SIRT1 expression in the kidneys and improved renal function including albuminuria, creatinine clearance, and renal histology $[117,118]$. Thus, caloric restriction activates sirtuins that may be beneficial in preventing the progression of DN.

Several studies have suggested that SIRT1 decreases mitochondrial oxidative stress and apoptosis through modulation of p53 [119], the AMPK/PGC-1 $\alpha$ pathway [120-122], the Nrf2 pathway [123], and the FoxO family [124], thereby providing protection against DN. SIRT1 also restrained renal inflammation and fibrosis under hyperglycemic conditions through HIF- $1 \alpha$ signaling in mesangial cells [125]. Podocyte-specific SIRT1 deletion in diabetic mice led to proteinuria and podocyte injury, and these changes were associated with renal inflammation due to hyperacetylation of STAT3/NF-KB [126]. In addition, SIRT1 modulated angiogenesis through downregulation of vascular endothelial growth factor (VEGF) and Flk-1 (VEGFR-2) expression in high glucose (HG)-treated podocytes and endothelial cells, but these effects were attenuated by the genetic elimination of SIRT1 [127].

SIRT1 may participate in the crosstalk between podocytes and tubular cells in DN. Podocyte-specific SIRT1 deletion caused severe mesangial expansion and podocyte loss [126], while SIRT1 overexpression in podocytes attenuated renal damage in diabetic mice [128]. SIRT1 deletion in proximal tubules also increased albuminuria, which upregulated the tight junction protein claudin-1, in streptozotocin (STZ)-induced diabetic mice [129]. Exposure of podocytes to medium obtained from proximal tubular cells cultured with HG downregulated SIRT1 and upregulated claudin-1 expression. These effects were abolished in podocytes exposed to medium from proximal tubular cells overexpressing SIRT1, even under HG conditions [129]. Based on these findings, Hasegawa et al. proposed a functional relationship between proximal tubules and podocytes, referred to as 'proximal tubule-podocyte communication' [129].

Recent research has demonstrated a role for SIRT1 in proximal tubule-podocyte communication in association with sodium-glucose cotransporter 2 (SGLT2). In diabetic kidneys, high glucose levels around the proximal tubules may trigger glucose transporter 2 (GLUT2)-mediated intracellular glucose uptake via SGLT2 upregulation, causing a concomitant decrease in SIRT1. An SGLT2 inhibitor recovered SIRT1 expression in diabetic mice and HG-treated proximal tubular cells [130], as well as AMPK phosphorylation [131]. Interplay between AMPK/SIRT1 signaling and sodium transport mechanisms in the kidney may partially explain the role of the SGLT2 inhibitor in ameliorating the development of DN [132].

The associations of sirtuins other than SIRT1 with DN have also been explored. SIRT3 overexpression suppressed HG-induced apoptosis by reducing ROS accumulation through modulation of Akt/FoxO signaling in proximal tubular cells [133]. On the other hand, SIRT3 suppression was associated with activation of TGF- $\beta /$ Smad 3 signaling and increased HIF- $1 \alpha$ accumulation, which subsequently caused abnormal glycolysis and kidney fibrosis in diabetic mice and proximal tubular cells [134]. SIRT4 overexpression led to downregulated expression of apoptosis-related proteins such as NADPH oxidase 1 (NOX1), Bcl-2-associated X protein (Bax), and phosphorylated p38, along with upregulated expression of Bcl-2, which was associated with attenuation of the inflammatory response in HG-simulated podocytes [135].

SIRT6 deletion exacerbated podocyte injury in diabetic mice, and SIRT6 overexpression with HG treatment protected against podocyte injury through epigenetic regulation of Notch1 and Notch4 transcription due to deacetylation of H3K9 [73]. SIRT6 was also found to regulate the immune response by activating M2 macrophages, which are protective against podocyte injury, in STZ-induced diabetic mice [136]. In a recent study, selective deletion of Nampt in proximal tubule cells of STZ-induced diabetic 
mice led to downregulation of SIRT6, which was accompanied by thickening of the tubular basement membrane, type IV collagen deposition, enhanced renal fibrosis, and albuminuria. Selective deletion of SIRT6 in the proximal tubules of diabetic mice caused a phenotype similar to that of Nampt knockout mice. Therefore, the Nampt-Sirt6 axis in proximal tubules was suggested to be a key player in the fibrogenic extracellular matrix remodeling associated with DN [137].

\subsection{Sirtuins in Chronic Kidney Disease}

Renal tubular fibrosis is a major pathognomonic phenomenon in CKD [138], and sirtuins have been demonstrated to play an important role in tubular fibrosis. SIRT1 knockout mice were found to have prominent tubular fibrosis in a model of unilateral ureter obstruction (UUO) [139]. Suppression of SIRT1 expression in mouse renal medullary interstitial cells resulted in substantial reduction of cellular resistance to oxidative stress [139]. In addition, SIRT1 activation inhibited tubular fibrosis in a 5/6 nephrectomy model and a UUO model $[140,141]$. SIRT1 expression was also found to be involved in the pathogenesis of chronic renal allograft dysfunction and chronic cyclosporine A (CsA) nephropathy. In rat kidneys with chronic allograft dysfunction, decreased SIRT1 was associated with mononuclear cell infiltration and interstitial fibrosis due to upregulation of inflammatory cytokines [142]. In a mouse model of chronic CsA nephropathy, SIRT1 expression was reduced according to the degree of tubulointerstitial fibrosis through the Nrf2 and PI3K/Akt/FoxO1 pathways [143].

Various mechanisms have been suggested to underlie the pathogenetic link between SIRT1 and the development of renal fibrosis. Endothelial SIRT1 expression may play an important role, as SIRT1 deletion in the endothelium of mice caused spontaneous interstitial fibrosis without glomerular involvement, even at a young age. Moreover, tubulointerstitial fibrosis after long-term folic acid treatment was aggravated in mice with endothelium-specific SIRT1 deletion [144]. Endothelial SIRT1 depletion also enhanced the senescence of pericapillary tubular endothelial cells, which manifested as impaired endothelial proliferation and increased expression of molecules in the Notch1 signaling pathway [145]. A role for sirtuins in the epithelial-to-mesenchymal transition (EMT) during the development of renal fibrosis has also been suggested [146]. SIRT1 up-regulation by resveratrol treatment ameliorated renal fibrosis in proximal tubular cells treated with TGF- $\beta$ in addition to a mouse model of UUO; this was found to be due to inhibition of the EMT through deacetylation of Smad4 and inhibition of matrix metalloproteinase-7 (MMP-7) [147].

Consistent with observations in AKI, pharmacological inhibition of SIRT2 resulted in reduction of renal interstitial fibrosis in UUO models $[148,149]$, which was accompanied by decreases in expression of epidermal growth factor receptor (EGFR), platelet-derived growth factor receptor- $\beta$ (PDGFR- $\beta$ ), STAT3 [148], and E3-ubiquitin ligase murine double-minute 2 (MDM2) [149]. In contrast, SIRT3 plays an important role in the endothelial-to-mesenchymal transition (EndoMT) associated with the vascular pathology of renal fibrosis [150]. EndoMT is a novel mechanism of renal fibrosis and is characterized by a phenotypic transition from vascular endothelial cells to myofibroblasts [151]. Honokiol, a pharmaceutical SIRT3 activator, decreased renal inflammation and fibrosis through regulation of mitochondrial dynamics via the NF-KB/TGF- $\beta 1 / S m a d$ signaling pathway [152]. SIRT6 knockout aggravated TGF- $\beta$-induced fibrosis in mouse tubular epithelial cells, while pharmacological inhibition of SIRT6 deacetylase activity by OSS_128167 induced kidney fibrosis in a mouse model of UUO through modulation of the $\mathrm{Wnt} / \beta$-catenin signaling pathway [74]. Therefore, various sirtuins appear to be involved in kidney fibrosis and related processes.

\section{Summary and Future Perspectives}

Sirtuins play critical roles in cellular homeostasis, and numerous published studies have revealed that sirtuins participate in various acute and chronic kidney diseases through the regulation of oxidative stress, apoptosis, inflammation, fibrosis, cell survival, ATP production and mitochondrial biogenesis (Figure 1, Table 1). Considering the fact that the functions of sirtuins have been well characterized in animal models, more research into the role of these proteins in human kidney diseases is warranted. 
Development of kidney-specific sirtuin activators will facilitate further investigation of sirtuins as novel therapeutic targets.

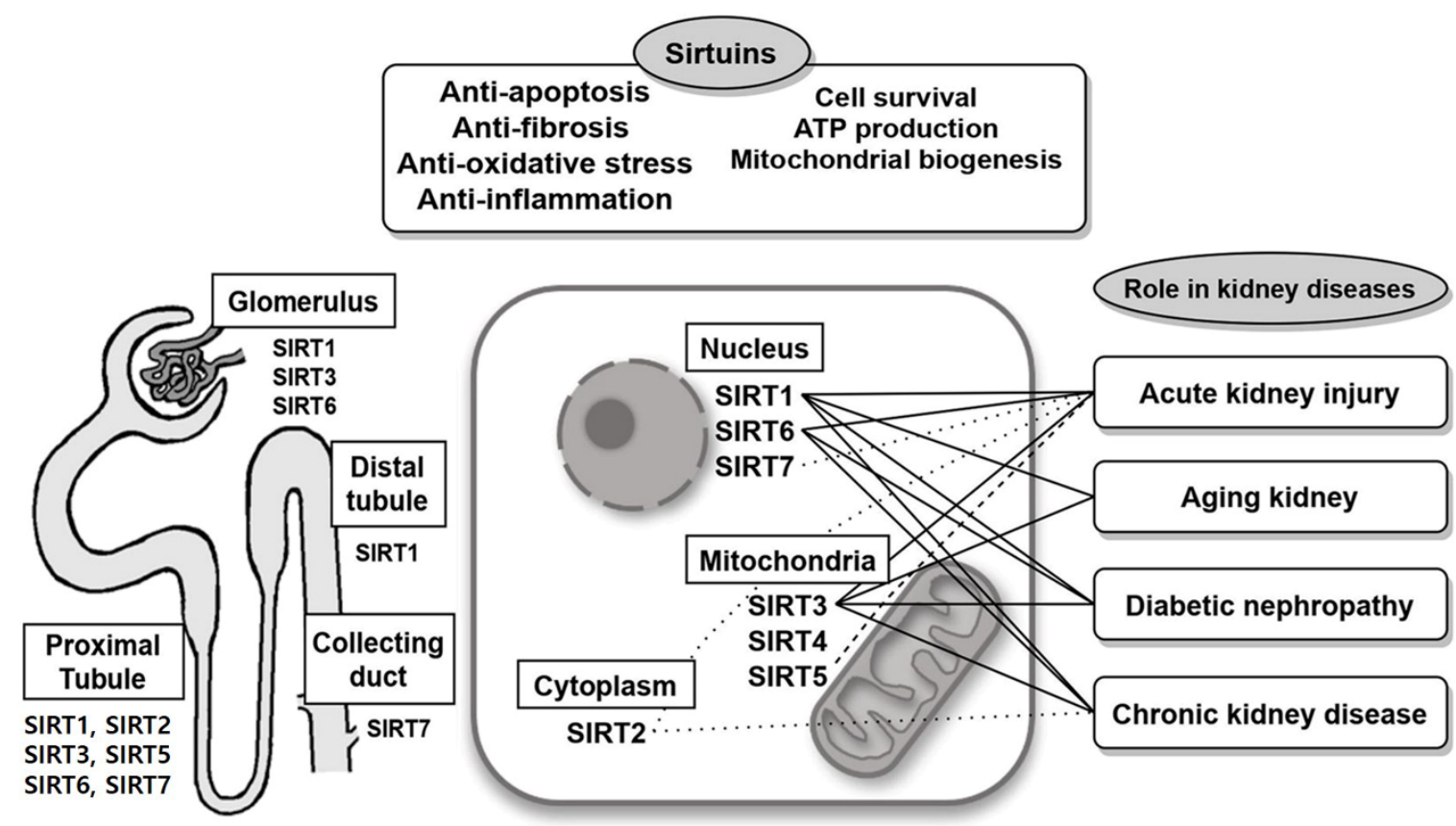

Figure 1. Implication of sirtuins in various kidney diseases associated with variable cellular location of sirtuins and associated pathways. The types of lines (solid line: attenuation of disease, dotted line: aggravation of disease, dash line: controversial) between each sirtuin with kidney disease were based on previous studies. 
Table 1. Pathophysiologic role of sirtuins in kidney diseases ( $\downarrow$ : decreases, $\uparrow$ : increases).

\begin{tabular}{|c|c|c|c|c|c|}
\hline \multicolumn{2}{|c|}{ Experimental Models } & Interventions & Renal Outcome/Phenotype & Mechanism & Ref \\
\hline \multicolumn{6}{|c|}{ SIRT1 } \\
\hline \multirow{6}{*}{ AKI } & \multirow{2}{*}{ I/R injury } & SRT-1720 & Apoptosis $\downarrow$ & SIRT1 $\uparrow \rightarrow$ acetylated p53 $\downarrow$ & [81] \\
\hline & & SRT-1720 & Mitochondrial biogenesis $\uparrow$ & $\begin{array}{c}\text { SIRT1 } \uparrow \rightarrow \text { PPAR } \gamma, \text { ATP levels } \uparrow \\
\text { SIRT1 } \uparrow \rightarrow \text { deacetylated PGC- } 1 \alpha \uparrow\end{array}$ & $\begin{array}{l}{[11]} \\
{[83]}\end{array}$ \\
\hline & \multirow[t]{2}{*}{ Cisplatin } & Tubule-specific SIRT1 Tg & $\begin{array}{c}\text { Apoptosis and ROS production } \downarrow \\
\text { Function and number of mitochondria } \\
\text { and peroxisome } \uparrow\end{array}$ & SIRT $1 \uparrow \rightarrow$ catalase, PGC- $1 \alpha \uparrow$ & [87] \\
\hline & & SRT-1720 & Apoptosis and inflammation $\downarrow$ & SIRT1 $\uparrow \rightarrow$ acetylated p53, NF- $\mathrm{kB}, \mathrm{TNF}-\alpha \downarrow$ & [88] \\
\hline & Sepsis & Resveratrol & $\begin{array}{l}\text { Oxidative stress } \downarrow \text {, mitochondrial } \\
\text { function } \uparrow\end{array}$ & SIRT1 $\uparrow \rightarrow$ acetylated SOD2 $\downarrow$ & [98] \\
\hline & Contrast & Resveratrol & Oxidative stress $\downarrow$ & SIRT1 $\uparrow \rightarrow$ PGC- $1 \alpha \uparrow$, FoxO1 $\uparrow$ & {$[100]$} \\
\hline \multirow[t]{2}{*}{ Aging } & Aging mice & $\begin{array}{c}\text { Doxycycline-inducible } \\
\text { podocyte-specific RNAi model for } \\
\text { SIRT1 (Pod-SIRT1 RNAi) }\end{array}$ & Oxidative stress $\uparrow$ & $\begin{array}{c}\text { SIRT } 1 \downarrow \rightarrow \text { PGC- } 1 \alpha \downarrow \text {, PPAR } \gamma \downarrow \text {, acetylated } \\
\text { FoxO3a, FoxO4, NF- } \mathrm{kB} \uparrow\end{array}$ & {$[107]$} \\
\hline & Aging mice & Resveratrol & Inflammation $\downarrow$ & SIRT1 $\uparrow \rightarrow$ Nrf2/HO- $1 \uparrow$, AMPK/PGC- $1 \alpha \uparrow$ & {$[109]$} \\
\hline \multirow{4}{*}{ DKD } & STZ-diabetic rats & Resveratrol & $\begin{array}{c}\text { Apoptosis and oxidative stress } \downarrow \\
\text { Angiogenesis } \downarrow\end{array}$ & $\begin{array}{c}\text { SIRT1 } \uparrow \rightarrow \text { acetylated p53 } \downarrow \\
\text { SIRT1 } \uparrow \rightarrow \text { Nrf } 2 \uparrow \\
\text { SIRT1 } \uparrow \rightarrow \text { phosphorylated FoxO1 } \downarrow \\
\text { SIRT1 } \uparrow \rightarrow \text { VEGF and Flk- } 1 \downarrow\end{array}$ & $\left.\begin{array}{l}{[119} \\
{[123} \\
{[124} \\
{[127}\end{array}\right]$ \\
\hline & $d b / d b$ mice & Resveratrol & $\begin{array}{c}\text { Mitochondrial biogenesis } \uparrow \\
\text { Oxidative stress and apoptosis } \downarrow\end{array}$ & $\begin{array}{c}\text { SIRT } 1 \uparrow \rightarrow \text { Mn-SOD } \uparrow, \text { AMPK } \uparrow \\
\text { SIRT } 1 \uparrow \rightarrow \text { AMPK/PGC- } 1 \alpha \uparrow, \text { PPAR } \alpha \uparrow\end{array}$ & $\left.\begin{array}{l}{[120]} \\
{[121} \\
{[122}\end{array}\right]$ \\
\hline & $d b / d b$ mice & $\begin{array}{c}\text { Podocyte-specific SIRT1 KO } \\
\text { (Podocin-Cre; SIRT1 } 1 \mathrm{fl} / \mathrm{fl} \text { ) } \\
\text { Proximal tubule-specific SIRT1 KO }\end{array}$ & $\begin{array}{c}\text { Inflammation and apoptosis } \uparrow \\
\text { Albuminuria and podocyte injury } \uparrow\end{array}$ & $\begin{array}{c}\text { SIRT } 1 \downarrow \rightarrow \text { acetylated p65, STAT3, FoxO4 } \uparrow \\
\text { SIRT1 } \downarrow \rightarrow \text { claudin- } 1 \uparrow\end{array}$ & $\left.\begin{array}{l}{[126} \\
{[129}\end{array}\right]$ \\
\hline & OVE26 mice & $\begin{array}{c}\text { Podocyte-specific SIRT1 } \\
\text { overexpression (Podocin-SIRT1 OV) }\end{array}$ & Podocyte injury $\downarrow$ & SIRT $1 \uparrow \rightarrow$ PGC- $1 \alpha \uparrow$ & {$[128]$} \\
\hline
\end{tabular}


Table 1. Cont.

\begin{tabular}{|c|c|c|c|c|c|}
\hline & Experimental Models & Interventions & Renal Outcome/Phenotype & Mechanism & Ref \\
\hline \multirow{5}{*}{ CKD } & UUO & $\begin{array}{l}\text { SIRT1 KO in endothelium } \\
\text { (Tie2-Cre with SIRT1 }^{\mathrm{F} / \mathrm{F}} \text { ) }\end{array}$ & $\begin{array}{c}\text { Apoptosis and fibrosis } \uparrow \\
\text { Senescence of peritubular capillary ECs } \uparrow\end{array}$ & $\begin{array}{l}\text { SIRT1 } \downarrow \rightarrow \text { renal COX2 } \downarrow \\
\text { SIRT } 1 \downarrow \rightarrow \text { Notch } 1 \uparrow\end{array}$ & $\begin{array}{l}{[139]} \\
{[145]}\end{array}$ \\
\hline & UUO & Resveratrol & Interstitial fibrosis $\downarrow$, EMT $\downarrow$ & $\begin{array}{l}\text { SIRT1 } \uparrow \rightarrow \text { acetylated Smad } 3 \downarrow \\
\text { SIRT } 1 \uparrow \rightarrow \text { MMP-7 } \downarrow\end{array}$ & {$[140]$} \\
\hline & UUO & SIRTinol, EX527 & Renal fibrosis $\downarrow$ & SIRT1, SIRT2 $\downarrow \rightarrow$ EGFR $\downarrow$, PDGFR $\downarrow$ & [148] \\
\hline & 5/6 nephrectomized mice & SIRT1 KO & Interstitial fibrosis $\uparrow$ & SIRT1 $\downarrow \rightarrow$ acetylated Smad3 $\uparrow$ & [141] \\
\hline & Folic acid nephropathy & Endothelial-deleted SIRT1 ${ }^{\text {endo-/- }}$ & Fibrotic response, angiogenesis $\uparrow$ & SIRT1 $\downarrow \rightarrow$ MMP-14 $\downarrow$ & [144] \\
\hline \multicolumn{6}{|c|}{ SIRT2 } \\
\hline \multirow[b]{2}{*}{ AKI } & Cisplatin & SIRT2 KO & Apoptosis, necroptosis, inflammation $\downarrow$ & SIRT2 $\downarrow \rightarrow \mathrm{MKP}-1 \uparrow \rightarrow \mathrm{p} 38, \mathrm{JNK} \downarrow$ & [90] \\
\hline & Sepsis & Genetic deletion of SIRT2 ${ }^{--}$ & Inflammation $\downarrow$ & $\begin{array}{c}\text { SIRT2 } \downarrow \rightarrow \text { CXCL2 } \downarrow, \text { CCL2 } \downarrow, \text { MKP-1 } \uparrow \rightarrow \\
\text { p38, JNK } \downarrow\end{array}$ & [34] \\
\hline \multirow{2}{*}{ CKD } & UUO & AGK2 & Tubulointerstitial fibrosis $\downarrow$ & SIRT2 $\downarrow \rightarrow$ MDM2-p53 $\downarrow$ & [149] \\
\hline & UUO & AGK2 & Renal fibrosis $\downarrow$ & SIRT1, SIRT2 $\downarrow \rightarrow$ EGFR $\downarrow$, PDGFR $\downarrow$ & [148] \\
\hline \multicolumn{6}{|c|}{ SIRT3 } \\
\hline \multirow[t]{2}{*}{ AKI } & Cisplatin & Genetic deletion of SIRT3 ${ }^{-/}$ & $\begin{array}{l}\text { Oxidative stress } \uparrow \text {, mitochondrial } \\
\text { function } \downarrow\end{array}$ & SIRT3 $\downarrow \rightarrow$ DRP1 $\uparrow$ & [91] \\
\hline & Contrast & Genetic deletion of SIRT3 ${ }^{-/}$ & Oxidative stress and apoptosis $\uparrow$ & SIRT3 $\downarrow \rightarrow$ MnSOD, catalase $\downarrow$ & [101] \\
\hline Aging & Aging mice & SIRT3 KO & Renal fibrosis $\uparrow$ & $\begin{array}{c}\text { SIRT3 } \downarrow \rightarrow \text { acetylated GSK-3 } \beta \uparrow \rightarrow \text { Smad3, } \\
\text { c-Jun, and } \beta \text {-catenin } \uparrow\end{array}$ & [112] \\
\hline DKD & STZ-diabetic mice & SIRT3 siRNA & Fibrosis and aberrant glycolysis $\uparrow$ & SIRT3 $\downarrow \rightarrow$ TGF- $\beta /$ smad $3 \uparrow$, HIF- $1 \alpha \uparrow$ & [134] \\
\hline \multirow[t]{2}{*}{ CKD } & UUO & $\begin{array}{l}\text { SIRT3 endothelial cell-specific } \mathrm{Tg} \\
\text { (SIRT3-TgEC) }\end{array}$ & $\begin{array}{c}\text { Renal fibrosis, EndoMT } \downarrow \text {, Oxidative } \\
\text { stress } \downarrow\end{array}$ & SIRT3 $\uparrow \rightarrow$ FoxO3a nuclear translocation $\uparrow$ & [150] \\
\hline & UUO & Honokiol & Mitochondrial fusion $\uparrow$, Inflammation $\downarrow$ & SIRT3 $\uparrow \rightarrow$ NF-kB/TGF- $\beta 1 /$ Smad $\downarrow$ & [152] \\
\hline \multicolumn{6}{|c|}{ SIRT5 } \\
\hline AKI & $\mathrm{I} / \mathrm{R}$ injury, Cisplatin & Genetic deletion of SIRT5 $5^{--}$ & Peroxisomal fatty acid oxidation $\uparrow$ & SIRT5 $\downarrow \rightarrow$ mtDNA $\uparrow$ & [65] \\
\hline
\end{tabular}


Table 1. Cont.

\begin{tabular}{|c|c|c|c|c|c|}
\hline \multicolumn{2}{|c|}{ Experimental Models } & Interventions & Renal Outcome/Phenotype & Mechanism & Ref \\
\hline \multicolumn{6}{|c|}{ SIRT6 } \\
\hline AKI & Cisplatin & SIRT6 Tg & Apoptosis $\downarrow$ & SIRT6 $\uparrow \rightarrow$ ERK $1 / 2 \downarrow$ & [94] \\
\hline \multirow{2}{*}{ DKD } & $\begin{array}{c}\text { STZ-treated } \\
\text { uninephrectomized mice }\end{array}$ & $\begin{array}{l}\text { Podocyte-specific SIRT6 KO } \\
\left(\text { Podocin-Cre }^{+} / \text {SIRT6 }^{\mathrm{fl} / \mathrm{fl}}\right)\end{array}$ & Podocyte injury $\uparrow$, Autophagy $\downarrow$ & SIRT6 $\downarrow \rightarrow$ acetylated H3K9 $\uparrow$, Notch1/4 $\uparrow$ & [73] \\
\hline & STZ-diabetic rats & SIRT6 overexpression & Podocyte injury $\downarrow$ & SIRT6 $\uparrow \rightarrow$ M2 macrophage $\uparrow$ & [136] \\
\hline CKD & UUO & OSS_128167 & Renal fibrosis $\uparrow$ & SIRT6 $\downarrow \rightarrow \beta$-catenin $\uparrow$, acetylated H3K56 $\uparrow$ & [74] \\
\hline \multicolumn{6}{|c|}{ SIRT7 } \\
\hline AKI & Cisplatin & Genetic deletion of SIRT7 ${ }^{--}$ & $\begin{array}{l}\text { Apoptosis, oxidative stress, } \\
\text { inflammation } \downarrow\end{array}$ & SIRT7 $\downarrow \rightarrow$ TNF- $\alpha \downarrow$, nuclear NF- $\kappa \mathrm{B} \downarrow$ & [79] \\
\hline
\end{tabular}

Abbreviations: AKI, acute kidney injury; AMPK, adenosine monophosphate-activated protein kinase; ATP, adenosine triphosphate; CCL2, C-C motif chemokine ligand 2; CKD, chronic kidney disease; COX2, cyclooxygenase-2; CXCL2, C-X-C motif chemokine ligand 2; DKD, diabetic kidney disease; DRP1, dynamin related protein; Endo or EC, endothelial cell; EGFR, epidermal growth factor receptor; EMT, epithelial-to-mesenchymal transition; EndoMT, endothelial-to-mesenchymal transition; ERK, extracellular-signal-regulated kinase; FoxO, forkhead box O; GSK-3 $\beta$, glycogen synthase kinase-3 $\beta$; HIF-1 $\alpha$, hypoxia-inducible factor- $1 \alpha$; HO-1, heme oxygenase-1; I/R, ischemia/reperfusion; JNK, c-Jun N-terminal kinase; KO, knockout; MDM2, E3-ubiquitin ligase murine double-minute 2; MKP-1, Mitogen-activated protein kinase-1; MMP, Matrix metalloproteinase; NF- $\mathrm{kB}$, Nuclear factor-kappa B; NOX, NADPH oxidase; Nrf2, nuclear factor erythroid 2-related factor 2; mtDNA, mitochondrial DNA; NF- $\mathrm{kB}$, nuclear factor-kappa B; OV, overexpression; PDGFR, Platelet-derived growth factor receptor; PGC- $1 \alpha$, peroxisome proliferator-activated receptor- $\gamma$ coactivator $1 \alpha$; PPAR, peroxisome proliferator-activated receptor; Pod, podocyte; siRNA, small interfering RNA; SIRT, sirtuin; SOD, superoxide dismutase; STAT3, Signal transducer and activator of transcription 3 ; STZ, streptozotocin; Tg, transgenic; TGF- $\beta 1$, transforming growth factor- $\beta 1$; TNF- $\alpha$, tumor necrosis factor- $\alpha$; UUO, unilateral ureteral obstruction; VEGF, Vascular endothelial growth factor. 
Author Contributions: Conceptualization, Y.A.H. and G.-J.K.; investigation, Y.A.H. and J.E.K.; data curation, Y.A.H. and M.J.; writing-original draft preparation and editing Y.A.H.; writing-review and editing, G.-J.K.; visualization, J.E.K. and M.J.; supervision, G.-J.K. All authors have read and agreed to the published version of the manuscript.

Funding: This work was supported by the National Research Foundation of Korea (NRF) grants funded by the Korea government (MSIT) (Y.A.H.; No. 2018R1C1B5045006, G.-J.K.; No. 2019R1F1A1062663). The authors also wish to acknowledge funding from the Catholic Medical Center Research Foundation in the program year of 2018 and a grant from the Clinical Research Institute (CMCDJ-P-2020-012) funded by the Catholic University of Korea Daejeon St. Mary's Hospital.

Conflicts of Interest: The authors declare no conflict of interest.

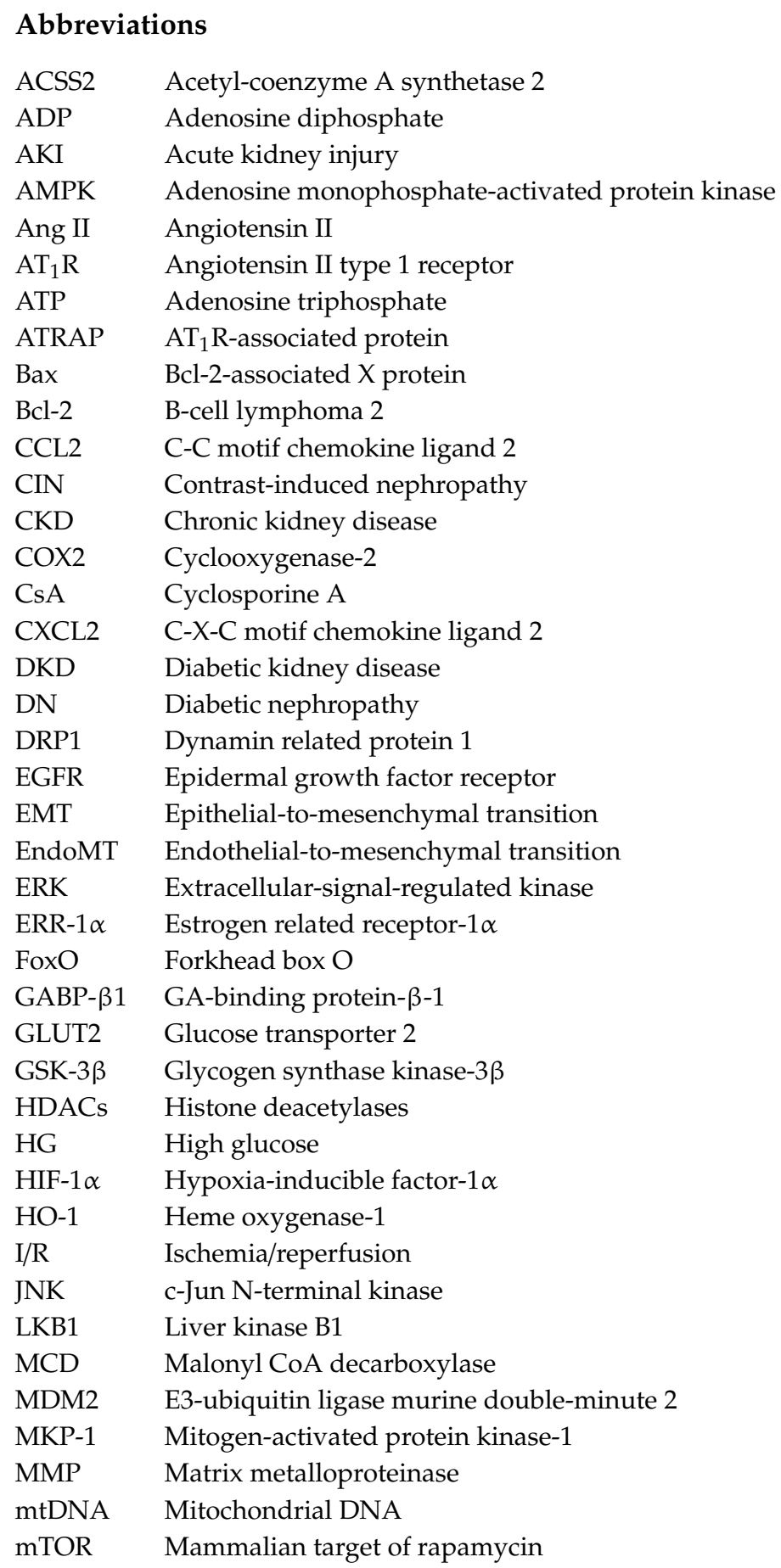




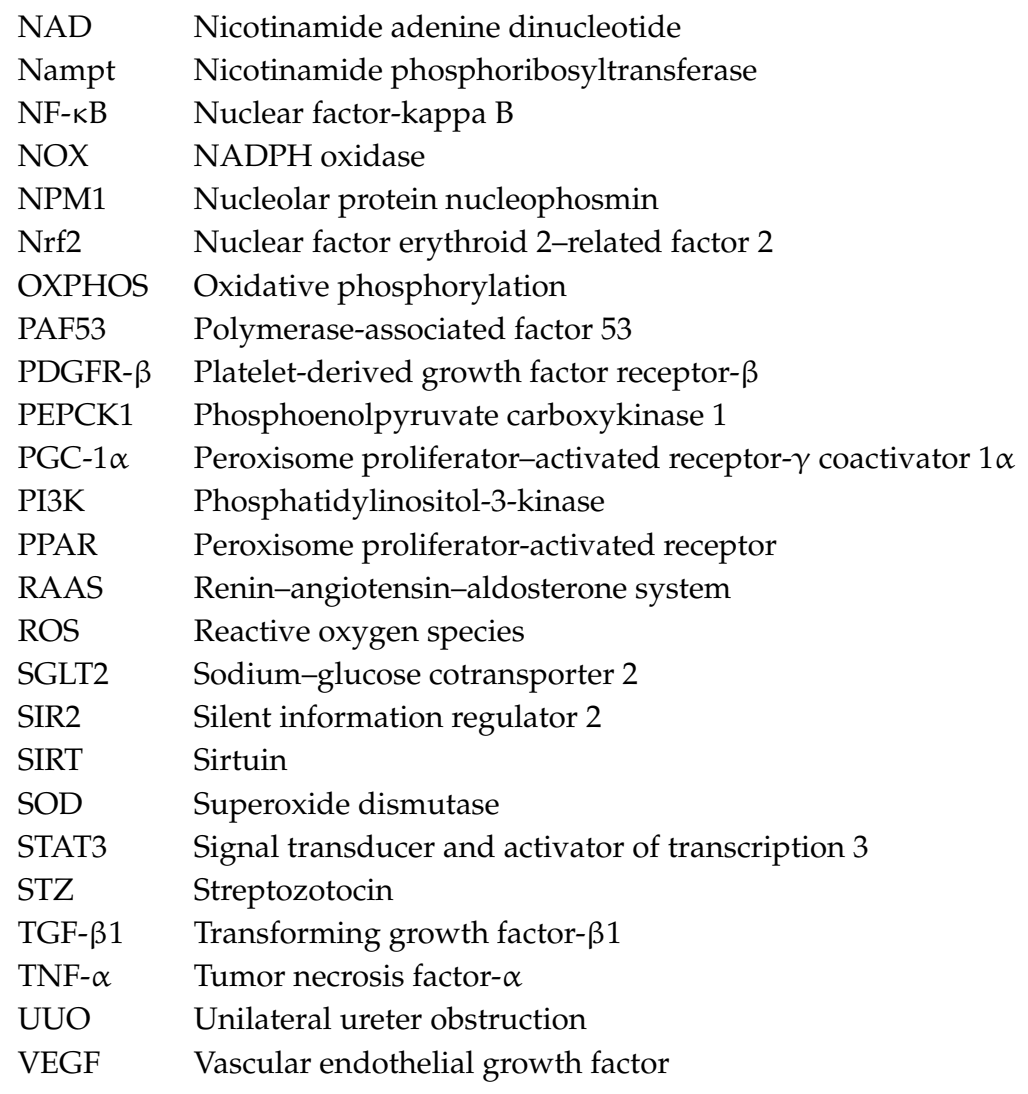

\section{References}

1. Finkel, T.; Deng, C.X.; Mostoslavsky, R. Recent progress in the biology and physiology of sirtuins. Nature 2009, 460, 587-591. [CrossRef] [PubMed]

2. Kim, S.; Benguria, A.; Lai, C.Y.; Jazwinski, S.M. Modulation of life-span by histone deacetylase genes in Saccharomyces cerevisiae. Mol. Biol. Cell 1999, 10, 3125-3136. [CrossRef] [PubMed]

3. Kaeberlein, M.; McVey, M.; Guarente, L. The SIR2/3/4 complex and SIR2 alone promote longevity in Saccharomyces cerevisiae by two different mechanisms. Genes Dev. 1999, 13, 2570-2580. [CrossRef] [PubMed]

4. Smith, B.C.; Hallows, W.C.; Denu, J.M. Mechanisms and molecular probes of sirtuins. Chem. Biol. 2008, 15, 1002-1013. [CrossRef]

5. Haigis, M.C.; Sinclair, D.A. Mammalian sirtuins: Biological insights and disease relevance. Annu. Rev. Pathol. 2010, 5, 253-295. [CrossRef]

6. Tong, C.; Morrison, A.; Mattison, S.; Qian, S.; Bryniarski, M.; Rankin, B.; Wang, J.; Thomas, D.P.; Li, J. Impaired SIRT1 nucleocytoplasmic shuttling in the senescent heart during ischemic stress. FASEB J. 2013, 27, 4332-4342. [CrossRef]

7. Tanno, M.; Sakamoto, J.; Miura, T.; Shimamoto, K.; Horio, Y. Nucleocytoplasmic shuttling of the NAD+-dependent histone deacetylase SIRT1. J. Biol. Chem. 2007, 282, 6823-6832. [CrossRef]

8. Morigi, M.; Perico, L.; Benigni, A. Sirtuins in Renal Health and Disease. J. Am. Soc. Nephrol. 2018, 29, 1799-1809. [CrossRef]

9. Rodgers, J.T.; Lerin, C.; Haas, W.; Gygi, S.P.; Spiegelman, B.M.; Puigserver, P. Nutrient control of glucose homeostasis through a complex of PGC-1 $\alpha$ and SIRT1. Nature 2005, 434, 113-118. [CrossRef]

10. Kume, S.; Haneda, M.; Kanasaki, K.; Sugimoto, T.; Araki, S.; Isono, M.; Isshiki, K.; Uzu, T.; Kashiwagi, A.; Koya, D. Silent information regulator 2 (SIRT1) attenuates oxidative stress-induced mesangial cell apoptosis via p53 deacetylation. Free Radic. Biol. Med. 2006, 40, 2175-2182. [CrossRef]

11. Khader, A.; Yang, W.L.; Kuncewitch, M.; Jacob, A.; Prince, J.M.; Asirvatham, J.R.; Nicastro, J.; Coppa, G.F.; Wang, P. Sirtuin 1 activation stimulates mitochondrial biogenesis and attenuates renal injury after ischemia-reperfusion. Transplantation 2014, 98, 148-156. [CrossRef] [PubMed] 
12. Kume, S.; Uzu, T.; Horiike, K.; Chin-Kanasaki, M.; Isshiki, K.; Araki, S.; Sugimoto, T.; Haneda, M.; Kashiwagi, A.; Koya, D. Calorie restriction enhances cell adaptation to hypoxia through Sirt1-dependent mitochondrial autophagy in mouse aged kidney. J. Clin. Investig. 2010, 120, 1043-1055. [CrossRef] [PubMed]

13. Moynihan, K.A.; Grimm, A.A.; Plueger, M.M.; Bernal-Mizrachi, E.; Ford, E.; Cras-Meneur, C.; Permutt, M.A.; Imai, S. Increased dosage of mammalian Sir2 in pancreatic beta cells enhances glucose-stimulated insulin secretion in mice. Cell Metab. 2005, 2, 105-117. [CrossRef] [PubMed]

14. Chen, D.; Bruno, J.; Easlon, E.; Lin, S.J.; Cheng, H.L.; Alt, F.W.; Guarente, L. Tissue-specific regulation of SIRT1 by calorie restriction. Genes Dev. 2008, 22, 1753-1757. [CrossRef]

15. Xie, J.; Zhang, X.; Zhang, L. Negative regulation of inflammation by SIRT1. Pharmacol. Res. 2013, 67, 60-67. [CrossRef] [PubMed]

16. Vaquero, A.; Scher, M.; Lee, D.; Erdjument-Bromage, H.; Tempst, P.; Reinberg, D. Human SirT1 interacts with histone $\mathrm{H} 1$ and promotes formation of facultative heterochromatin. Mol. Cell 2004, 16, 93-105. [CrossRef]

17. Vaziri, H.; Dessain, S.K.; Ng Eaton, E.; Imai, S.I.; Frye, R.A.; Pandita, T.K.; Guarente, L.; Weinberg, R.A. hSIR2(SIRT1) functions as an NAD-dependent p53 deacetylase. Cell 2001, 107, 149-159. [CrossRef]

18. Yeung, F.; Hoberg, J.E.; Ramsey, C.S.; Keller, M.D.; Jones, D.R.; Frye, R.A.; Mayo, M.W. Modulation of NF-kappaB-dependent transcription and cell survival by the SIRT1 deacetylase. EMBO J. 2004, 23, 2369-2380. [CrossRef]

19. Bernier, M.; Paul, R.K.; Martin-Montalvo, A.; Scheibye-Knudsen, M.; Song, S.; He, H.J.; Armour, S.M.; Hubbard, B.P.; Bohr, V.A.; Wang, L.; et al. Negative regulation of STAT3 protein-mediated cellular respiration by SIRT1 protein. J. Biol. Chem. 2011, 286, 19270-19279. [CrossRef]

20. Burnett, C.; Valentini, S.; Cabreiro, F.; Goss, M.; Somogyvari, M.; Piper, M.D.; Hoddinott, M.; Sutphin, G.L.; Leko, V.; McElwee, J.J.; et al. Absence of effects of Sir2 overexpression on lifespan in C. elegans and Drosophila. Nature 2011, 477, 482-485. [CrossRef]

21. Lim, J.H.; Lee, Y.M.; Chun, Y.S.; Chen, J.; Kim, J.E.; Park, J.W. Sirtuin 1 modulates cellular responses to hypoxia by deacetylating hypoxia-inducible factor $1 \alpha$. Mol. Cell 2010, 38, 864-878. [CrossRef] [PubMed]

22. Laemmle, A.; Lechleiter, A.; Roh, V.; Schwarz, C.; Portmann, S.; Furer, C.; Keogh, A.; Tschan, M.P.; Candinas, D.; Vorburger, S.A.; et al. Inhibition of SIRT1 impairs the accumulation and transcriptional activity of HIF- $1 \alpha$ protein under hypoxic conditions. PLoS ONE 2012, 7, e33433. [CrossRef] [PubMed]

23. Yacoub, R.; Lee, K.; He, J.C. The Role of SIRT1 in Diabetic Kidney Disease. Front. Endocrinol. (Lausanne) 2014, 5, 166. [CrossRef]

24. Scarpulla, R.C. Metabolic control of mitochondrial biogenesis through the PGC-1 family regulatory network. Biochim. Biophys. Acta 2011, 1813, 1269-1278. [CrossRef] [PubMed]

25. Price, N.L.; Gomes, A.P.; Ling, A.J.; Duarte, F.V.; Martin-Montalvo, A.; North, B.J.; Agarwal, B.; Ye, L.; Ramadori, G.; Teodoro, J.S.; et al. SIRT1 is required for AMPK activation and the beneficial effects of resveratrol on mitochondrial function. Cell Metab. 2012, 15, 675-690. [CrossRef] [PubMed]

26. Cetrullo, S.; D'Adamo, S.; Tantini, B.; Borzi, R.M.; Flamigni, F. mTOR, AMPK, and Sirt1: Key Players in Metabolic Stress Management. Crit. Rev. Eukaryot. Gene Expr. 2015, 25, 59-75. [CrossRef]

27. Zhou, Y.; Song, T.; Peng, J.; Zhou, Z.; Wei, H.; Zhou, R.; Jiang, S.; Peng, J. SIRT1 suppresses adipogenesis by activating $W n t / \beta$-catenin signaling in vivo and in vitro. Oncotarget 2016, 7, 77707-77720. [CrossRef]

28. North, B.J.; Marshall, B.L.; Borra, M.T.; Denu, J.M.; Verdin, E. The human Sir2 ortholog, SIRT2, is an $\mathrm{NAD}^{+}$-dependent tubulin deacetylase. Mol. Cell 2003, 11, 437-444. [CrossRef]

29. Jing, H.; Lin, H. Sirtuins in epigenetic regulation. Chem. Rev. 2015, 115, 2350-2375. [CrossRef]

30. Vaquero, A.; Scher, M.B.; Lee, D.H.; Sutton, A.; Cheng, H.L.; Alt, F.W.; Serrano, L.; Sternglanz, R.; Reinberg, D. SirT2 is a histone deacetylase with preference for histone H4 Lys 16 during mitosis. Genes Dev. 2006, 20, 1256-1261. [CrossRef]

31. Das, C.; Lucia, M.S.; Hansen, K.C.; Tyler, J.K. CBP/p300-mediated acetylation of histone H3 on lysine 56. Nature 2009, 459, 113-117. [CrossRef] [PubMed]

32. Serrano, L.; Martinez-Redondo, P.; Marazuela-Duque, A.; Vazquez, B.N.; Dooley, S.J.; Voigt, P.; Beck, D.B.; Kane-Goldsmith, N.; Tong, Q.; Rabanal, R.M.; et al. The tumor suppressor SirT2 regulates cell cycle progression and genome stability by modulating the mitotic deposition of H4K20 methylation. Genes Dev. 2013, 27, 639-653. [CrossRef] [PubMed]

33. Zhang, M.; Pan, Y.; Dorfman, R.G.; Yin, Y.; Zhou, Q.; Huang, S.; Liu, J.; Zhao, S. Sirtinol promotes PEPCK1 degradation and inhibits gluconeogenesis by inhibiting deacetylase SIRT2. Sci. Rep. 2017, 7, 7. [CrossRef] 
34. Jung, Y.J.; Lee, A.S.; Nguyen-Thanh, T.; Kim, D.; Kang, K.P.; Lee, S.; Park, S.K.; Kim, W. SIRT2 Regulates LPS-Induced Renal Tubular CXCL2 and CCL2 Expression. J. Am. Soc. Nephrol. 2015, 26, 1549-1560. [CrossRef] [PubMed]

35. Jing, E.; Gesta, S.; Kahn, C.R. SIRT2 regulates adipocyte differentiation through FoxO1 acetylation/ deacetylation. Cell Metab. 2007, 6, 105-114. [CrossRef] [PubMed]

36. Wang, F.; Nguyen, M.; Qin, F.X.; Tong, Q. SIRT2 deacetylates FOXO3a in response to oxidative stress and caloric restriction. Aging Cell 2007, 6, 505-514. [CrossRef] [PubMed]

37. Ramakrishnan, G.; Davaakhuu, G.; Kaplun, L.; Chung, W.C.; Rana, A.; Atfi, A.; Miele, L.; Tzivion, G. Sirt2 deacetylase is a novel AKT binding partner critical for AKT activation by insulin. J. Biol. Chem. 2014, 289, 6054-6066. [CrossRef]

38. Scher, M.B.; Vaquero, A.; Reinberg, D. SirT3 is a nuclear NAD ${ }^{+}$-dependent histone deacetylase that translocates to the mitochondria upon cellular stress. Genes Dev. 2007, 21, 920-928. [CrossRef]

39. Hirschey, M.D.; Shimazu, T.; Capra, J.A.; Pollard, K.S.; Verdin, E. SIRT1 and SIRT3 deacetylate homologous substrates: AceCS1,2 and HMGCS1,2. Aging (Albany NY) 2011, 3, 635-642. [CrossRef]

40. Hebert, A.S.; Dittenhafer-Reed, K.E.; Yu, W.; Bailey, D.J.; Selen, E.S.; Boersma, M.D.; Carson, J.J.; Tonelli, M.; Balloon, A.J.; Higbee, A.J.; et al. Calorie restriction and SIRT3 trigger global reprogramming of the mitochondrial protein acetylome. Mol. Cell 2013, 49, 186-199. [CrossRef]

41. Qiu, X.; Brown, K.; Hirschey, M.D.; Verdin, E.; Chen, D. Calorie restriction reduces oxidative stress by SIRT3-mediated SOD2 activation. Cell Metab. 2010, 12, 662-667. [CrossRef] [PubMed]

42. Chen, C.J.; Fu, Y.C.; Yu, W.; Wang, W. SIRT3 protects cardiomyocytes from oxidative stress-mediated cell death by activating NF-kappaB. Biochem. Biophys. Res. Commun. 2013, 430, 798-803. [CrossRef] [PubMed]

43. Pillai, V.B.; Sundaresan, N.R.; Kim, G.; Gupta, M.; Rajamohan, S.B.; Pillai, J.B.; Samant, S.; Ravindra, P.V.; Isbatan, A.; Gupta, M.P. Exogenous NAD blocks cardiac hypertrophic response via activation of the SIRT3-LKB1-AMP-activated kinase pathway. J. Biol. Chem. 2010, 285, 3133-3144. [CrossRef] [PubMed]

44. Shi, T.; Wang, F.; Stieren, E.; Tong, Q. SIRT3, a mitochondrial sirtuin deacetylase, regulates mitochondrial function and thermogenesis in brown adipocytes. J. Biol. Chem. 2005, 280, 13560-13567. [CrossRef] [PubMed]

45. Sundaresan, N.R.; Gupta, M.; Kim, G.; Rajamohan, S.B.; Isbatan, A.; Gupta, M.P. Sirt3 blocks the cardiac hypertrophic response by augmenting Foxo3a-dependent antioxidant defense mechanisms in mice. J. Clin. Investig. 2009, 119, 2758-2771. [CrossRef]

46. Rardin, M.J.; Newman, J.C.; Held, J.M.; Cusack, M.P.; Sorensen, D.J.; Li, B.; Schilling, B.; Mooney, S.D.; Kahn, C.R.; Verdin, E.; et al. Label-free quantitative proteomics of the lysine acetylome in mitochondria identifies substrates of SIRT3 in metabolic pathways. Proc. Natl. Acad. Sci. USA 2013, 110, 6601-6606. [CrossRef]

47. Koyama, T.; Kume, S.; Koya, D.; Araki, S.; Isshiki, K.; Chin-Kanasaki, M.; Sugimoto, T.; Haneda, M.; Sugaya, T.; Kashiwagi, A.; et al. SIRT3 attenuates palmitate-induced ROS production and inflammation in proximal tubular cells. Free Radic. Biol. Med. 2011, 51, 1258-1267. [CrossRef]

48. Haigis, M.C.; Mostoslavsky, R.; Haigis, K.M.; Fahie, K.; Christodoulou, D.C.; Murphy, A.J.; Valenzuela, D.M.; Yancopoulos, G.D.; Karow, M.; Blander, G.; et al. SIRT4 inhibits glutamate dehydrogenase and opposes the effects of calorie restriction in pancreatic beta cells. Cell 2006, 126, 941-954. [CrossRef]

49. Anderson, K.A.; Huynh, F.K.; Fisher-Wellman, K.; Stuart, J.D.; Peterson, B.S.; Douros, J.D.; Wagner, G.R.; Thompson, J.W.; Madsen, A.S.; Green, M.F.; et al. SIRT4 Is a Lysine Deacylase that Controls Leucine Metabolism and Insulin Secretion. Cell Metab. 2017, 25, 838-855.e815. [CrossRef]

50. Laurent, G.; German, N.J.; Saha, A.K.; De Boer, V.C.; Davies, M.; Koves, T.R.; Dephoure, N.; Fischer, F.; Boanca, G.; Vaitheesvaran, B.; et al. SIRT4 coordinates the balance between lipid synthesis and catabolism by repressing malonyl CoA decarboxylase. Mol. Cell 2013, 50, 686-698. [CrossRef]

51. Laurent, G.; de Boer, V.C.; Finley, L.W.; Sweeney, M.; Lu, H.; Schug, T.T.; Cen, Y.; Jeong, S.M.; Li, X.; Sauve, A.A.; et al. SIRT4 represses peroxisome proliferator-activated receptor $\alpha$ activity to suppress hepatic fat oxidation. Mol. Cell Biol. 2013, 33, 4552-4561. [CrossRef] [PubMed]

52. Ho, L.; Titus, A.S.; Banerjee, K.K.; George, S.; Lin, W.; Deota, S.; Saha, A.K.; Nakamura, K.; Gut, P.; Verdin, E.; et al. SIRT4 regulates ATP homeostasis and mediates a retrograde signaling via AMPK. Aging (Albany NY) 2013, 5, 835-849. [CrossRef] [PubMed] 
53. Jeong, S.M.; Xiao, C.; Finley, L.W.; Lahusen, T.; Souza, A.L.; Pierce, K.; Li, Y.H.; Wang, X.; Laurent, G.; German, N.J.; et al. SIRT4 has tumor-suppressive activity and regulates the cellular metabolic response to DNA damage by inhibiting mitochondrial glutamine metabolism. Cancer Cell 2013, 23, 450-463. [CrossRef] [PubMed]

54. Hershberger, K.A.; Martin, A.S.; Hirschey, M.D. Role of $\mathrm{NAD}(+)$ and mitochondrial sirtuins in cardiac and renal diseases. Nat. Rev. Nephrol. 2017, 13, 213-225. [CrossRef]

55. Schlicker, C.; Gertz, M.; Papatheodorou, P.; Kachholz, B.; Becker, C.F.; Steegborn, C. Substrates and regulation mechanisms for the human mitochondrial sirtuins Sirt3 and Sirt5. J. Mol. Biol. 2008, 382, 790-801. [CrossRef]

56. Park, J.; Chen, Y.; Tishkoff, D.X.; Peng, C.; Tan, M.; Dai, L.; Xie, Z.; Zhang, Y.; Zwaans, B.M.; Skinner, M.E.; et al. SIRT5-mediated lysine desuccinylation impacts diverse metabolic pathways. Mol. Cell 2013, 50, 919-930. [CrossRef]

57. Chen, X.F.; Tian, M.X.; Sun, R.Q.; Zhang, M.L.; Zhou, L.S.; Jin, L.; Chen, L.L.; Zhou, W.J.; Duan, K.L.; Chen, Y.J.; et al. SIRT5 inhibits peroxisomal ACOX1 to prevent oxidative damage and is downregulated in liver cancer. EMBO Rep. 2018, 19, e45124. [CrossRef]

58. De Moura, M.B.; Uppala, R.; Zhang, Y.; Van Houten, B.; Goetzman, E.S. Overexpression of mitochondrial sirtuins alters glycolysis and mitochondrial function in HEK293 cells. PLoS ONE 2014, 9, e106028.

59. Du, J.; Zhou, Y.; Su, X.; Yu, J.J.; Khan, S.; Jiang, H.; Kim, J.; Woo, J.; Kim, J.H.; Choi, B.H.; et al. Sirt5 is a NAD-dependent protein lysine demalonylase and desuccinylase. Science 2011, 334, 806-809. [CrossRef]

60. Kumar, S.; Lombard, D.B. Functions of the sirtuin deacylase SIRT5 in normal physiology and pathobiology. Crit. Rev. Biochem. Mol. Biol. 2018, 53, 311-334. [CrossRef]

61. Rardin, M.J.; He, W.; Nishida, Y.; Newman, J.C.; Carrico, C.; Danielson, S.R.; Guo, A.; Gut, P.; Sahu, A.K.; $\mathrm{Li}$, B.; et al. SIRT5 regulates the mitochondrial lysine succinylome and metabolic networks. Cell Metab. 2013, 18, 920-933. [CrossRef] [PubMed]

62. Tan, M.; Peng, C.; Anderson, K.A.; Chhoy, P.; Xie, Z.; Dai, L.; Park, J.; Chen, Y.; Huang, H.; Zhang, Y.; et al. Lysine glutarylation is a protein posttranslational modification regulated by SIRT5. Cell Metab. 2014, 19, 605-617. [CrossRef] [PubMed]

63. Nishida, Y.; Rardin, M.J.; Carrico, C.; He, W.; Sahu, A.K.; Gut, P.; Najjar, R.; Fitch, M.; Hellerstein, M.; Gibson, B.W.; et al. SIRT5 Regulates both Cytosolic and Mitochondrial Protein Malonylation with Glycolysis as a Major Target. Mol. Cell 2015, 59, 321-332. [CrossRef] [PubMed]

64. Yu, J.; Sadhukhan, S.; Noriega, L.G.; Moullan, N.; He, B.; Weiss, R.S.; Lin, H.; Schoonjans, K.; Auwerx, J. Metabolic characterization of a Sirt5 deficient mouse model. Sci. Rep. 2013, 3, 2806. [CrossRef]

65. Chiba, T.; Peasley, K.D.; Cargill, K.R.; Maringer, K.V.; Bharathi, S.S.; Mukherjee, E.; Zhang, Y.; Holtz, A.; Basisty, N.; Yagobian, S.D.; et al. Sirtuin 5 Regulates Proximal Tubule Fatty Acid Oxidation to Protect against AKI. J. Am. Soc. Nephrol. 2019, 30, 2384-2398. [CrossRef]

66. Sosnowska, B.; Mazidi, M.; Penson, P.; Gluba-Brzozka, A.; Rysz, J.; Banach, M. The sirtuin family members SIRT1, SIRT3 and SIRT6: Their role in vascular biology and atherogenesis. Atherosclerosis 2017, 265, $275-282$. [CrossRef]

67. Liszt, G.; Ford, E.; Kurtev, M.; Guarente, L. Mouse Sir2 homolog SIRT6 is a nuclear ADP-ribosyltransferase. J. Biol. Chem. 2005, 280, 21313-21320. [CrossRef]

68. Masri, S.; Rigor, P.; Cervantes, M.; Ceglia, N.; Sebastian, C.; Xiao, C.; Roqueta-Rivera, M.; Deng, C.; Osborne, T.F.; Mostoslavsky, R.; et al. Partitioning circadian transcription by SIRT6 leads to segregated control of cellular metabolism. Cell 2014, 158, 659-672. [CrossRef]

69. Lerrer, B.; Gertler, A.A.; Cohen, H.Y. The complex role of SIRT6 in carcinogenesis. Carcinogenesis 2016, 37, 108-118. [CrossRef]

70. Zhong, L.; D’Urso, A.; Toiber, D.; Sebastian, C.; Henry, R.E.; Vadysirisack, D.D.; Guimaraes, A.; Marinelli, B.; Wikstrom, J.D.; Nir, T.; et al. The histone deacetylase Sirt6 regulates glucose homeostasis via Hif1 $\alpha$. Cell 2010, 140, 280-293. [CrossRef]

71. Sundaresan, N.R.; Vasudevan, P.; Zhong, L.; Kim, G.; Samant, S.; Parekh, V.; Pillai, V.B.; Ravindra, P.V.; Gupta, M.; Jeevanandam, V.; et al. The sirtuin SIRT6 blocks IGF-Akt signaling and development of cardiac hypertrophy by targeting c-Jun. Nat. Med. 2012, 18, 1643-1650. [CrossRef] [PubMed]

72. Huang, W.; Liu, H.; Zhu, S.; Woodson, M.; Liu, R.; Tilton, R.G.; Miller, J.D.; Zhang, W. Sirt6 deficiency results in progression of glomerular injury in the kidney. Aging (Albany NY) 2017, 9, 1069-1083. [CrossRef] [PubMed] 
73. Liu, M.; Liang, K.; Zhen, J.; Zhou, M.; Wang, X.; Wang, Z.; Wei, X.; Zhang, Y.; Sun, Y.; Zhou, Z.; et al. Sirt6 deficiency exacerbates podocyte injury and proteinuria through targeting Notch signaling. Nat. Commun. 2017, 8, 413. [CrossRef] [PubMed]

74. Cai, J.; Liu, Z.; Huang, X.; Shu, S.; Hu, X.; Zheng, M.; Tang, C.; Liu, Y.; Chen, G.; Sun, L.; et al. The deacetylase sirtuin 6 protects against kidney fibrosis by epigenetically blocking $\beta$-catenin target gene expression. Kidney Int. 2020, 97, 106-118. [CrossRef]

75. Ford, E.; Voit, R.; Liszt, G.; Magin, C.; Grummt, I.; Guarente, L. Mammalian Sir2 homolog SIRT7 is an activator of RNA polymerase I transcription. Genes Dev. 2006, 20, 1075-1080. [CrossRef]

76. Kiran, S.; Anwar, T.; Kiran, M.; Ramakrishna, G. Sirtuin 7 in cell proliferation, stress and disease: Rise of the Seventh Sirtuin! Cell. Signal. 2015, 27, 673-682. [CrossRef]

77. Vazquez, B.N.; Thackray, J.K.; Serrano, L. Sirtuins and DNA damage repair: SIRT7 comes to play. Nucleus 2017, 8, 107-115. [CrossRef]

78. Li, L.; Shi, L.; Yang, S.; Yan, R.; Zhang, D.; Yang, J.; He, L.; Li, W.; Yi, X.; Sun, L.; et al. SIRT7 is a histone desuccinylase that functionally links to chromatin compaction and genome stability. Nat. Commun. 2016, 7, 12235. [CrossRef]

79. Miyasato, Y.; Yoshizawa, T.; Sato, Y.; Nakagawa, T.; Miyasato, Y.; Kakizoe, Y.; Kuwabara, T.; Adachi, M.; Ianni, A.; Braun, T.; et al. Sirtuin 7 Deficiency Ameliorates Cisplatin-induced Acute Kidney Injury Through Regulation of the Inflammatory Response. Sci. Rep. 2018, 8, 5927. [CrossRef]

80. Wakino, S.; Hasegawa, K.; Itoh, H. Sirtuin and metabolic kidney disease. Kidney Int. 2015, 88, 691-698. [CrossRef]

81. Fan, H.; Yang, H.C.; You, L.; Wang, Y.Y.; He, W.J.; Hao, C.M. The histone deacetylase, SIRT1, contributes to the resistance of young mice to ischemia/reperfusion-induced acute kidney injury. Kidney Int. 2013, 83, 404-413. [CrossRef] [PubMed]

82. Shi, S.; Lei, S.; Tang, C.; Wang, K.; Xia, Z. Melatonin attenuates acute kidney ischemia/reperfusion injury in diabetic rats by activation of the SIRT1/Nrf2/HO-1 signaling pathway. Biosci. Rep. 2019, 39, BSR20181614. [CrossRef] [PubMed]

83. Funk, J.A.; Schnellmann, R.G. Accelerated recovery of renal mitochondrial and tubule homeostasis with SIRT1/PGC-1 $\alpha$ activation following ischemia-reperfusion injury. Toxicol. Appl. Pharmacol. 2013, 273, 345-354. [CrossRef] [PubMed]

84. Pan, J.S.; Huang, L.; Belousova, T.; Lu, L.; Yang, Y.; Reddel, R.; Chang, A.; Ju, H.; DiMattia, G.; Tong, Q.; et al. Stanniocalcin-1 inhibits renal ischemia/reperfusion injury via an AMP-activated protein kinase-dependent pathway. J. Am. Soc. Nephrol. 2015, 26, 364-378. [CrossRef]

85. Peerapanyasut, W.; Kobroob, A.; Palee, S.; Chattipakorn, N.; Wongmekiat, O. Bisphenol A aggravates renal ischemia-reperfusion injury by disrupting mitochondrial homeostasis and $\mathrm{N}$-acetylcysteine mitigates the injurious outcomes. IUBMB Life 2020, 72, 758-770. [CrossRef] [PubMed]

86. Gao, Z.; Chen, X.; Fan, Y.; Zhu, K.; Shi, M.; Ding, G. Sirt6 attenuates hypoxia-induced tubular epithelial cell injury via targeting G2/M phase arrest. J. Cell Physiol. 2020, 235, 3463-3473. [CrossRef]

87. Hasegawa, K.; Wakino, S.; Yoshioka, K.; Tatematsu, S.; Hara, Y.; Minakuchi, H.; Sueyasu, K.; Washida, N.; Tokuyama, H.; Tzukerman, M.; et al. Kidney-specific overexpression of Sirt1 protects against acute kidney injury by retaining peroxisome function. J. Biol. Chem. 2010, 285, 13045-13056. [CrossRef]

88. Kim, J.Y.; Jo, J.; Kim, K.; An, H.J.; Gwon, M.G.; Gu, H.; Kim, H.J.; Yang, A.Y.; Kim, S.W.; Jeon, E.J.; et al. Pharmacological Activation of Sirt1 Ameliorates Cisplatin-Induced Acute Kidney Injury by Suppressing Apoptosis, Oxidative Stress, and Inflammation in Mice. Antioxidants (Basel) 2019, 8, 322. [CrossRef]

89. Qi, Z.; Li, Z.; Li, W.; Liu, Y.; Wang, C.; Lin, H.; Liu, J.; Li, P. Pseudoginsengenin DQ Exhibits Therapeutic Effects in Cisplatin-Induced Acute Kidney Injury via Sirt1/NF-kB and Caspase Signaling Pathway without Compromising Its Antitumor Activity in Mice. Molecules 2018, 23, 3038. [CrossRef]

90. Jung, Y.J.; Park, W.; Kang, K.P.; Kim, W. SIRT2 is involved in cisplatin-induced acute kidney injury through regulation of mitogen-activated protein kinase phosphatase-1. Nephrol. Dial. Transpl. 2020, 35, 1145-1156. [CrossRef]

91. Morigi, M.; Perico, L.; Rota, C.; Longaretti, L.; Conti, S.; Rottoli, D.; Novelli, R.; Remuzzi, G.; Benigni, A. Sirtuin 3-dependent mitochondrial dynamic improvements protect against acute kidney injury. J. Clin. Investig. 2015, 125, 715-726. [CrossRef] [PubMed] 
92. Ortega-Dominguez, B.; Aparicio-Trejo, O.E.; Garcia-Arroyo, F.E.; Leon-Contreras, J.C.; Tapia, E.; Molina-Jijon, E.; Hernandez-Pando, R.; Sanchez-Lozada, L.G.; Barrera-Oviedo, D.; Pedraza-Chaverri, J. Curcumin prevents cisplatin-induced renal alterations in mitochondrial bioenergetics and dynamic. Food Chem. Toxicol. 2017, 107, 373-385. [CrossRef] [PubMed]

93. Li, Y.; Ye, Z.; Lai, W.; Rao, J.; Huang, W.; Zhang, X.; Yao, Z.; Lou, T. Activation of Sirtuin 3 by Silybin Attenuates Mitochondrial Dysfunction in Cisplatin-induced Acute Kidney Injury. Front. Pharmacol. 2017, 8, 178. [CrossRef] [PubMed]

94. Li, Z.; Xu, K.; Zhang, N.; Amador, G.; Wang, Y.; Zhao, S.; Li, L.; Qiu, Y.; Wang, Z. Overexpressed SIRT6 attenuates cisplatin-induced acute kidney injury by inhibiting ERK1/2 signaling. Kidney Int. 2018, 93, 881-892. [CrossRef]

95. Li, W.; Yang, Y.; Li, Y.; Zhao, Y.; Jiang, H. Sirt5 Attenuates Cisplatin-Induced Acute Kidney Injury through Regulation of Nrf2/HO-1 and Bcl-2. BioMed Res. Int. 2019, 2019, 4745132. [CrossRef]

96. Gao, Q.; Zhu, H. The Overexpression of Sirtuin1 (SIRT1) Alleviated Lipopolysaccharide (LPS)-Induced Acute Kidney Injury (AKI) via Inhibiting the Activation of Nucleotide-Binding Oligomerization Domain-Like Receptors (NLR) Family Pyrin Domain Containing 3 (NLRP3) Inflammasome. Med. Sci. Monit. 2019, 25, 2718-2726.

97. Zhang, Y.; Wang, L.; Meng, L.; Cao, G.; Wu, Y. Sirtuin 6 overexpression relieves sepsis-induced acute kidney injury by promoting autophagy. Cell Cycle 2019, 18, 425-436. [CrossRef]

98. Xu, S.; Gao, Y.; Zhang, Q.; Wei, S.; Chen, Z.; Dai, X.; Zeng, Z.; Zhao, K.S. SIRT1/3 Activation by Resveratrol Attenuates Acute Kidney Injury in a Septic Rat Model. Oxidative Med. Cell Longev. 2016, 2016, 7296092. [CrossRef]

99. Kim, J.E.; Bae, S.Y.; Ahn, S.Y.; Kwon, Y.J.; Ko, G.J. The role of nuclear factor erythroid-2-related factor 2 expression in radiocontrast-induced nephropathy. Sci. Rep. 2019, 9, 2608. [CrossRef]

100. Hong, Y.A.; Bae, S.Y.; Ahn, S.Y.; Kim, J.; Kwon, Y.J.; Jung, W.Y.; Ko, G.J. Resveratrol Ameliorates Contrast Induced Nephropathy Through the Activation of SIRT1-PGC-1 $\alpha$-Foxo1 Signaling in Mice. Kidney Blood Press. Res. 2017, 42, 641-653. [CrossRef]

101. Zhao, W.; Zhang, L.; Chen, R.; Lu, H.; Sui, M.; Zhu, Y.; Zeng, L. SIRT3 Protects Against Acute Kidney Injury via AMPK/mTOR-Regulated Autophagy. Front. Physiol. 2018, 9, 1526. [CrossRef] [PubMed]

102. Zhou, Q.; Wang, X.; Shao, X.; Wang, H.; Liu, X.; Ke, X.; Xiong, C.; Wei, L.; Zou, H. tert-Butylhydroquinone Treatment Alleviates Contrast-Induced Nephropathy in Rats by Activating the Nrf2/Sirt3/SOD2 Signaling Pathway. Oxidative Med. Cell. Longev. 2019, 2019, 4657651. [CrossRef] [PubMed]

103. Martin, J.E.; Sheaff, M.T. Renal ageing. J. Pathol. 2007, 211, 198-205. [CrossRef] [PubMed]

104. Lim, J.H.; Kim, E.N.; Kim, M.Y.; Chung, S.; Shin, S.J.; Kim, H.W.; Yang, C.W.; Kim, Y.S.; Chang, Y.S.; Park, C.W.; et al. Age-associated molecular changes in the kidney in aged mice. Oxidative Med. Cell. Longev. 2012, 2012, 171383. [CrossRef] [PubMed]

105. Ryu, D.R.; Yu, M.R.; Kong, K.H.; Kim, H.; Kwon, S.H.; Jeon, J.S.; Han, D.C.; Noh, H. Sirt1-hypoxia-inducible factor- $1 \alpha$ interaction is a key mediator of tubulointerstitial damage in the aged kidney. Aging Cell 2019, 18, e12904. [CrossRef]

106. Hsu, S.C.; Huang, S.M.; Chen, A.; Sun, C.Y.; Lin, S.H.; Chen, J.S.; Liu, S.T.; Hsu, Y.J. Resveratrol increases anti-aging Klotho gene expression via the activating transcription factor 3/c-Jun complex-mediated signaling pathway. Int. J. Biochem. Cell Biol. 2014, 53, 361-371. [CrossRef]

107. Chuang, P.Y.; Cai, W.; Li, X.; Fang, L.; Xu, J.; Yacoub, R.; He, J.C.; Lee, K. Reduction in podocyte SIRT1 accelerates kidney injury in aging mice. Am. J. Physiol. Renal Physiol. 2017, 313, F621-f628. [CrossRef]

108. Ning, Y.C.; Cai, G.Y.; Zhuo, L.; Gao, J.J.; Dong, D.; Cui, S.; Feng, Z.; Shi, S.Z.; Bai, X.Y.; Sun, X.F.; et al. Short-term calorie restriction protects against renal senescence of aged rats by increasing autophagic activity and reducing oxidative damage. Mech. Ageing Dev. 2013, 134, 570-579. [CrossRef]

109. Kim, E.N.; Lim, J.H.; Kim, M.Y.; Ban, T.H.; Jang, I.A.; Yoon, H.E.; Park, C.W.; Chang, Y.S.; Choi, B.S. Resveratrol, an Nrf2 activator, ameliorates aging-related progressive renal injury. Aging (Albany NY) 2018, 10, 83-99. [CrossRef]

110. Benigni, A.; Corna, D.; Zoja, C.; Sonzogni, A.; Latini, R.; Salio, M.; Conti, S.; Rottoli, D.; Longaretti, L.; Cassis, P.; et al. Disruption of the Ang II type 1 receptor promotes longevity in mice. J. Clin. Investig. 2009, 119, 524-530. [CrossRef] 
111. Uneda, K.; Wakui, H.; Maeda, A.; Azushima, K.; Kobayashi, R.; Haku, S.; Ohki, K.; Haruhara, K.; Kinguchi, S.; Matsuda, M.; et al. Angiotensin II Type 1 Receptor-Associated Protein Regulates Kidney Aging and Lifespan Independent of Angiotensin. J. Am. Heart Assoc. 2017, 6, e006120. [CrossRef] [PubMed]

112. Sundaresan, N.R.; Bindu, S.; Pillai, V.B.; Samant, S.; Pan, Y.; Huang, J.Y.; Gupta, M.; Nagalingam, R.S.; Wolfgeher, D.; Verdin, E.; et al. SIRT3 Blocks Aging-Associated Tissue Fibrosis in Mice by Deacetylating and Activating Glycogen Synthase Kinase 3ß. Mol. Cell Biol. 2015, 36, 678-692. [CrossRef] [PubMed]

113. Zhang, N.; Li, Z.; Mu, W.; Li, L.; Liang, Y.; Lu, M.; Wang, Z.; Qiu, Y.; Wang, Z. Calorie restriction-induced SIRT6 activation delays aging by suppressing NF-кB signaling. Cell Cycle 2016, 15, 1009-1018. [CrossRef] [PubMed]

114. Anson, R.M.; Guo, Z.; de Cabo, R.; Iyun, T.; Rios, M.; Hagepanos, A.; Ingram, D.K.; Lane, M.A.; Mattson, M.P. Intermittent fasting dissociates beneficial effects of dietary restriction on glucose metabolism and neuronal resistance to injury from calorie intake. Proc. Natl. Acad. Sci. USA 2003, 100, 6216-6220. [CrossRef] [PubMed]

115. Svendsen, P.F.; Jensen, F.K.; Holst, J.J.; Haugaard, S.B.; Nilas, L.; Madsbad, S. The effect of a very low calorie diet on insulin sensitivity, beta cell function, insulin clearance, incretin hormone secretion, androgen levels and body composition in obese young women. Scand. J. Clin. Lab. Investig. 2012, 72, 410-419. [CrossRef]

116. Friedman, A.N.; Chambers, M.; Kamendulis, L.M.; Temmerman, J. Short-term changes after a weight reduction intervention in advanced diabetic nephropathy. Clin. J. Am. Soc. Nephrol. 2013, 8, 1892-1898. [CrossRef] [PubMed]

117. Tikoo, K.; Tripathi, D.N.; Kabra, D.G.; Sharma, V.; Gaikwad, A.B. Intermittent fasting prevents the progression of type I diabetic nephropathy in rats and changes the expression of Sir2 and p53. FEBS Lett. 2007, 581, 1071-1078. [CrossRef]

118. Kitada, M.; Takeda, A.; Nagai, T.; Ito, H.; Kanasaki, K.; Koya, D. Dietary restriction ameliorates diabetic nephropathy through anti-inflammatory effects and regulation of the autophagy via restoration of Sirt1 in diabetic Wistar fatty (fa/fa) rats: A model of type 2 diabetes. Exp. Diabetes Res. 2011, 2011, 908185. [CrossRef]

119. Wang, X.L.; Wu, L.Y.; Zhao, L.; Sun, L.N.; Liu, H.Y.; Liu, G.; Guan, G.J. SIRT1 activator ameliorates the renal tubular injury induced by hyperglycemia in vivo and in vitro via inhibiting apoptosis. Biomed. Pharmacother. 2016, 83, 41-50. [CrossRef]

120. Kitada, M.; Kume, S.; Imaizumi, N.; Koya, D. Resveratrol improves oxidative stress and protects against diabetic nephropathy through normalization of Mn-SOD dysfunction in AMPK/SIRT1-independent pathway. Diabetes 2011, 60, 634-643. [CrossRef]

121. Kim, M.Y.; Lim, J.H.; Youn, H.H.; Hong, Y.A.; Yang, K.S.; Park, H.S.; Chung, S.; Ko, S.H.; Shin, S.J.; Choi, B.S.; et al. Resveratrol prevents renal lipotoxicity and inhibits mesangial cell glucotoxicity in a manner dependent on the AMPK-SIRT1-PGC-1 $\alpha$ axis in $d b / d b$ mice. Diabetologia 2013, 56, 204-217. [CrossRef] [PubMed]

122. Park, H.S.; Lim, J.H.; Kim, M.Y.; Kim, Y.; Hong, Y.A.; Choi, S.R.; Chung, S.; Kim, H.W.; Choi, B.S.; Kim, Y.S.; et al. Resveratrol increases AdipoR1 and AdipoR2 expression in type 2 diabetic nephropathy. J. Transl. Med. 2016, 14, 176. [CrossRef] [PubMed]

123. Huang, K.; Huang, J.; Xie, X.; Wang, S.; Chen, C.; Shen, X.; Liu, P.; Huang, H. Sirt1 resists advanced glycation end products-induced expressions of fibronectin and TGF- $\beta 1$ by activating the Nrf2/ARE pathway in glomerular mesangial cells. Free Radic. Biol. Med. 2013, 65, 528-540. [CrossRef] [PubMed]

124. Wu, L.; Zhang, Y.; Ma, X.; Zhang, N.; Qin, G. The effect of resveratrol on FoxO1 expression in kidneys of diabetic nephropathy rats. Mol. Biol. Rep. 2012, 39, 9085-9093. [CrossRef]

125. Shao, Y.; Lv, C.; Wu, C.; Zhou, Y.; Wang, Q. Mir-217 promotes inflammation and fibrosis in high glucose cultured rat glomerular mesangial cells via Sirt1/HIF-1 $\alpha$ signaling pathway. Diabetes Metab. Res. Rev. 2016, 32, 534-543. [CrossRef]

126. Liu, R.; Zhong, Y.; Li, X.; Chen, H.; Jim, B.; Zhou, M.M.; Chuang, P.Y.; He, J.C. Role of transcription factor acetylation in diabetic kidney disease. Diabetes 2014, 63, 2440-2453. [CrossRef]

127. Wen, D.; Huang, X.; Zhang, M.; Zhang, L.; Chen, J.; Gu, Y.; Hao, C.M. Resveratrol attenuates diabetic nephropathy via modulating angiogenesis. PLoS ONE 2013, 8, e82336. [CrossRef]

128. Hong, Q.; Zhang, L.; Das, B.; Li, Z.; Liu, B.; Cai, G.; Chen, X.; Chuang, P.Y.; He, J.C.; Lee, K. Increased podocyte Sirtuin-1 function attenuates diabetic kidney injury. Kidney Int. 2018, 93, 1330-1343. [CrossRef] 
129. Hasegawa, K.; Wakino, S.; Simic, P.; Sakamaki, Y.; Minakuchi, H.; Fujimura, K.; Hosoya, K.; Komatsu, M.; Kaneko, Y.; Kanda, T.; et al. Renal tubular Sirt1 attenuates diabetic albuminuria by epigenetically suppressing Claudin-1 overexpression in podocytes. Nat. Med. 2013, 19, 1496-1504. [CrossRef]

130. Umino, H.; Hasegawa, K.; Minakuchi, H.; Muraoka, H.; Kawaguchi, T.; Kanda, T.; Tokuyama, H.; Wakino, S.; Itoh, H. High Basolateral Glucose Increases Sodium-Glucose Cotransporter 2 and Reduces Sirtuin-1 in Renal Tubules through Glucose Transporter-2 Detection. Sci. Rep. 2018, 8, 6791. [CrossRef]

131. Hawley, S.A.; Ford, R.J.; Smith, B.K.; Gowans, G.J.; Mancini, S.J.; Pitt, R.D.; Day, E.A.; Salt, I.P.; Steinberg, G.R.; Hardie, D.G. The Na+/Glucose Cotransporter Inhibitor Canagliflozin Activates AMPK by Inhibiting Mitochondrial Function and Increasing Cellular AMP Levels. Diabetes 2016, 65, 2784-2794. [CrossRef] [PubMed]

132. Packer, M. Interplay of adenosine monophosphate-activated protein kinase/sirtuin-1 activation and sodium influx inhibition mediates the renal benefits of sodium-glucose co-transporter-2 inhibitors in type 2 diabetes: A novel conceptual framework. Diabetes Obes. Metab. 2020, 22, 734-742. [CrossRef] [PubMed]

133. Jiao, X.; Li, Y.; Zhang, T.; Liu, M.; Chi, Y. Role of Sirtuin3 in high glucose-induced apoptosis in renal tubular epithelial cells. Biochem. Biophys. Res. Commun. 2016, 480, 387-393. [CrossRef] [PubMed]

134. Srivastava, S.P.; Li, J.; Kitada, M.; Fujita, H.; Yamada, Y.; Goodwin, J.E.; Kanasaki, K.; Koya, D. SIRT3 deficiency leads to induction of abnormal glycolysis in diabetic kidney with fibrosis. Cell Death Dis. 2018, 9, 997. [CrossRef]

135. Shi, J.X.; Wang, Q.J.; Li, H.; Huang, Q. SIRT4 overexpression protects against diabetic nephropathy by inhibiting podocyte apoptosis. Exp. Ther. Med. 2017, 13, 342-348. [CrossRef]

136. Ji, L.; Chen, Y.; Wang, H.; Zhang, W.; He, L.; Wu, J.; Liu, Y. Overexpression of Sirt6 promotes M2 macrophage transformation, alleviating renal injury in diabetic nephropathy. Int. J. Oncol. 2019, 55, 103-115. [CrossRef]

137. Muraoka, H.; Hasegawa, K.; Sakamaki, Y.; Minakuchi, H.; Kawaguchi, T.; Yasuda, I.; Kanda, T.; Tokuyama, H.; Wakino, S.; Itoh, H. Role of Nampt-Sirt6 Axis in Renal Proximal Tubules in Extracellular Matrix Deposition in Diabetic Nephropathy. Cell Rep. 2019, 27, 199-212.e195. [CrossRef]

138. Humphreys, B.D. Mechanisms of Renal Fibrosis. Annu. Rev. Physiol. 2018, 80, 309-326. [CrossRef]

139. He, W.; Wang, Y.; Zhang, M.Z.; You, L.; Davis, L.S.; Fan, H.; Yang, H.C.; Fogo, A.B.; Zent, R.; Harris, R.C.; et al. Sirt1 activation protects the mouse renal medulla from oxidative injury. J. Clin. Investig. 2010, 120, 1056-1068. [CrossRef]

140. Li, J.; Qu, X.; Ricardo, S.D.; Bertram, J.F.; Nikolic-Paterson, D.J. Resveratrol inhibits renal fibrosis in the obstructed kidney: Potential role in deacetylation of Smad3. Am. J. Pathol. 2010, 177, 1065-1071. [CrossRef]

141. Huang, X.Z.; Wen, D.; Zhang, M.; Xie, Q.; Ma, L.; Guan, Y.; Ren, Y.; Chen, J.; Hao, C.M. Sirt1 activation ameliorates renal fibrosis by inhibiting the TGF- $\beta / S m a d 3$ pathway. J. Cell Biochem. 2014, 115, 996-1005. [CrossRef] [PubMed]

142. Xia, Y.; Deng, J.; Zhou, Q.; Shao, X.; Yang, X.; Sha, M.; Zou, H. Expression and significance of Sirt1 in renal allografts at the early stage of chronic renal allograft dysfunction. Transpl. Immunol. 2018, 48, 18-25. [CrossRef] [PubMed]

143. Koh, E.S.; Kim, S.; Kim, M.; Hong, Y.A.; Shin, S.J.; Park, C.W.; Chang, Y.S.; Chung, S.; Kim, H.S. D-Pinitol alleviates cyclosporine A-induced renal tubulointerstitial fibrosis via activating Sirt1 and Nrf2 antioxidant pathways. Int. J. Mol. Med. 2018, 41, 1826-1834. [CrossRef] [PubMed]

144. Vasko, R.; Xavier, S.; Chen, J.; Lin, C.H.; Ratliff, B.; Rabadi, M.; Maizel, J.; Tanokuchi, R.; Zhang, F.; Cao, J.; et al. Endothelial sirtuin 1 deficiency perpetrates nephrosclerosis through downregulation of matrix metalloproteinase-14: Relevance to fibrosis of vascular senescence. J. Am. Soc. Nephrol. 2014, 25, $276-291$. [CrossRef]

145. Kida, Y.; Zullo, J.A.; Goligorsky, M.S. Endothelial sirtuin 1 inactivation enhances capillary rarefaction and fibrosis following kidney injury through Notch activation. Biochem. Biophys. Res. Commun. 2016, 478, 1074-1079. [CrossRef]

146. Kalluri, R.; Weinberg, R.A. The basics of epithelial-mesenchymal transition. J. Clin. Investig. 2009, 119, 1420-1428. [CrossRef]

147. Xiao, Z.; Chen, C.; Meng, T.; Zhang, W.; Zhou, Q. Resveratrol attenuates renal injury and fibrosis by inhibiting transforming growth factor- $\beta$ pathway on matrix metalloproteinase 7. Exp. Biol. Med. (Maywood) 2016, 241, 140-146. [CrossRef] 
148. Ponnusamy, M.; Zhou, X.; Yan, Y.; Tang, J.; Tolbert, E.; Zhao, T.C.; Gong, R.; Zhuang, S. Blocking sirtuin 1 and 2 inhibits renal interstitial fibroblast activation and attenuates renal interstitial fibrosis in obstructive nephropathy. J. Pharmacol. Exp. Ther. 2014, 350, 243-256. [CrossRef]

149. He, F.F.; You, R.Y.; Ye, C.; Lei, C.T.; Tang, H.; Su, H.; Zhang, C. Inhibition of SIRT2 Alleviates Fibroblast Activation and Renal Tubulointerstitial Fibrosis via MDM2. Cell Physiol. Biochem. 2018, 46, 451-460. [CrossRef]

150. Lin, J.R.; Zheng, Y.J.; Zhang, Z.B.; Shen, W.L.; Li, X.D.; Wei, T.; Ruan, C.C.; Chen, X.H.; Zhu, D.L.; Gao, P.J. Suppression of Endothelial-to-Mesenchymal Transition by SIRT (Sirtuin) 3 Alleviated the Development of Hypertensive Renal Injury. Hypertension 2018, 72, 350-360. [CrossRef]

151. Cruz-Solbes, A.S.; Youker, K. Epithelial to Mesenchymal Transition (EMT) and Endothelial to Mesenchymal Transition (EndMT): Role and Implications in Kidney Fibrosis. Results Probl. Cell Differ. 2017, 60, 345-372. [PubMed]

152. Quan, Y.; Park, W.; Jin, J.; Kim, W.; Park, S.K.; Kang, K.P. Sirtuin 3 Activation by Honokiol Decreases Unilateral Ureteral Obstruction-Induced Renal Inflammation and Fibrosis via Regulation of Mitochondrial Dynamics and the Renal NF-kB-TGF- $\beta 1 / S m a d$ Signaling Pathway. Int. J. Mol. Sci. 2020, 21, 402. [CrossRef] [PubMed]

(C) 2020 by the authors. Licensee MDPI, Basel, Switzerland. This article is an open access article distributed under the terms and conditions of the Creative Commons Attribution (CC BY) license (http://creativecommons.org/licenses/by/4.0/). 